\title{
əIntense Interactions between Ocean Waves and Currents Observed in the Lofoten Maelstrom
}

\author{
$\emptyset$ yvind Saetra, ${ }^{\mathrm{a}}$ Trygve Halsne, ${ }^{\mathrm{a}, \mathrm{b}}$ Ana Carrasco, ${ }^{\mathrm{a}}$ Øyvind Breivik, ${ }^{\mathrm{a}, \mathrm{b}}$ Torstein Pedersen, ${ }^{\mathrm{c}}$ And \\ KAI HÅKON CHRISTENSEN ${ }^{\mathrm{a}}$

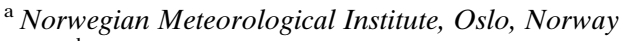 \\ ${ }^{\mathrm{b}}$ University of Bergen, Bergen, Norway \\ ${ }^{\mathrm{c}}$ Nortek AS, Oslo, Norway
}

(Manuscript received 20 November 2020, in final form 3 September 2021)

\begin{abstract}
The Lofoten Maelstrom has been known for centuries as one of the strongest open-ocean tidal currents in the world, estimated to reach $3 \mathrm{~m} \mathrm{~s}^{-1}$, and by some estimates as much as $5 \mathrm{~m} \mathrm{~s}^{-1}$. The strong current gives rise to choppy seas when waves enter the Moskenes Sound, making the area extremely difficult to navigate. Despite its reputation, few studies of its strength exist, and no stationary in situ measurements for longer time periods have been made due to the challenging conditions. By deploying for the first time in situ wave and current instruments, we confirm some previous estimates of the strength of the current. We also show that its strength is strongly connected with wave breaking. From a consideration of specific forcing terms in the dynamical energy balance equation for waves on a variable current, we assess the impact of the underlying current using a convenient metric formulated as a function of the horizontal current gradients. We find that the horizontal gradients are a likely explanation for the observed enhanced wave breaking during strong currents at a rising tide.
\end{abstract}

KEYWORDS: Currents; Gravity waves; Wave breaking; Tides

\section{Introduction}

The Lofoten Maelstrom, locally (and hereafter) referred to as Moskstraumen, is a very strong open-ocean tidal current in northern Norway. It is caused by the large difference in tidal amplitude between Vestfjorden and the Norwegian Sea. Moskstraumen is located in the Moskenes Sound between the Lofoten peninsula and the island of Mosken (Figs. 1a and 2). The Lofoten peninsula acts as a barrier for the northwardpropagating tidal Kelvin wave, building up a water level difference. The tidal currents are thus driven by the pressure gradient across the Moskenes Sound (Gjevik et al. 1997; Moe et al. 2002; Ommundsen 2002). Its ferocity made it notorious as early as the Viking Age (Guerber 1909), with notable references in the classical literature like "A Descent into the Maelström" by Edgar Allan Poe (Poe 1841), and Twenty Thousand Leagues Under the Seas by Jules Verne (Verne 1869). In the first nautical chart covering Scandinavia, the "Carta Marina" (see Fig. 1b), the Swedish priest Olaus Magnus depicted the current as a giant whirlpool engulfing ships (Peterson et al. 1996). The word Maelstrom originates from the Dutch "malen" meaning grinding, referring to the ocean eddies generated by the current. These were thought of as sinks of water, whereby the water was drawn into the holes of large magical millstones grinding salt on the ocean floor (Guerber 1909), supposedly explaining the mechanism that makes the ocean salty.

Maritime navigation in the Moskenes Sound is considered safe only on slack tide. A recent incident involved the fishing

¿ Denotes content that is immediately available upon publication as open access.

Corresponding author: Trygve Halsne, trygve.halsne@met.no vessel Iselin (see Fig. 1c), which capsized in the middle of the Moskenes Sound, fortunately without loss of human life (Smith 2017). The Norwegian Pilot Guide (Den norske los 2018) claims that ships with up to 10 -kt speed (about $5 \mathrm{~m} \mathrm{~s}^{-1}$ ) have been unable to advance. Their claim, however, is based solely on observations from ships and other eye-witness accounts.

Model studies (Gjevik et al. 1997; Moe et al. 2002; Ommundsen 2002) have estimated current speeds to reach $3 \mathrm{~m} \mathrm{~s}^{-1}$, using a 500-m resolution barotropic ocean circulation model, but the authors noted the lack of observations to corroborate their results. Ship-based measurements with an acoustic Doppler current profiler (ADCP) were taken in 2009, where current speeds up to $1.7 \mathrm{~m} \mathrm{~s}^{-1}$ (Lynge 2011) were observed. The Institute of Marine Research tried to deploy current moorings in 1977, but the speed of the current made it too risky, and the attempt was abandoned (S. Sundby 2020, personal communication). Thus, to our knowledge, the ADCP observations reported here are the first in situ observations of its kind in Moskstraumen. That is, simultaneous observations of waves and currents spanning a considerable time period.

The theory describing wave-current interactions is well established (e.g., Longuet-Higgins and Stewart 1960; Phillips 1977; Andrews and McIntyre 1978; Phillips 1984). However, the response of surface waves to different current regimes at both mesoscale and submesocale is still an active field of research (e.g., Gallet and Young 2014; Quilfen et al. 2018; Vincent 1979; Ardhuin et al. 2017; Gemmrich and Garrett 2012; Masson 1996; Romero et al. 2020; Marechal and Ardhuin 2021). Recent studies include further development of modeling frameworks taking wave-current interactions into account (e.g., Moreira and Peregrine 2012; Ardhuin et al. 2012; Romero 2019; Villas Bôas et al. 2020) as well observational case studies (e.g., Quilfen and Chapron 2019; Romero et al. 2017; Kudryavtsev et al. 2017). In nearshore environments, wave-current interactions depend on the local wave and current 

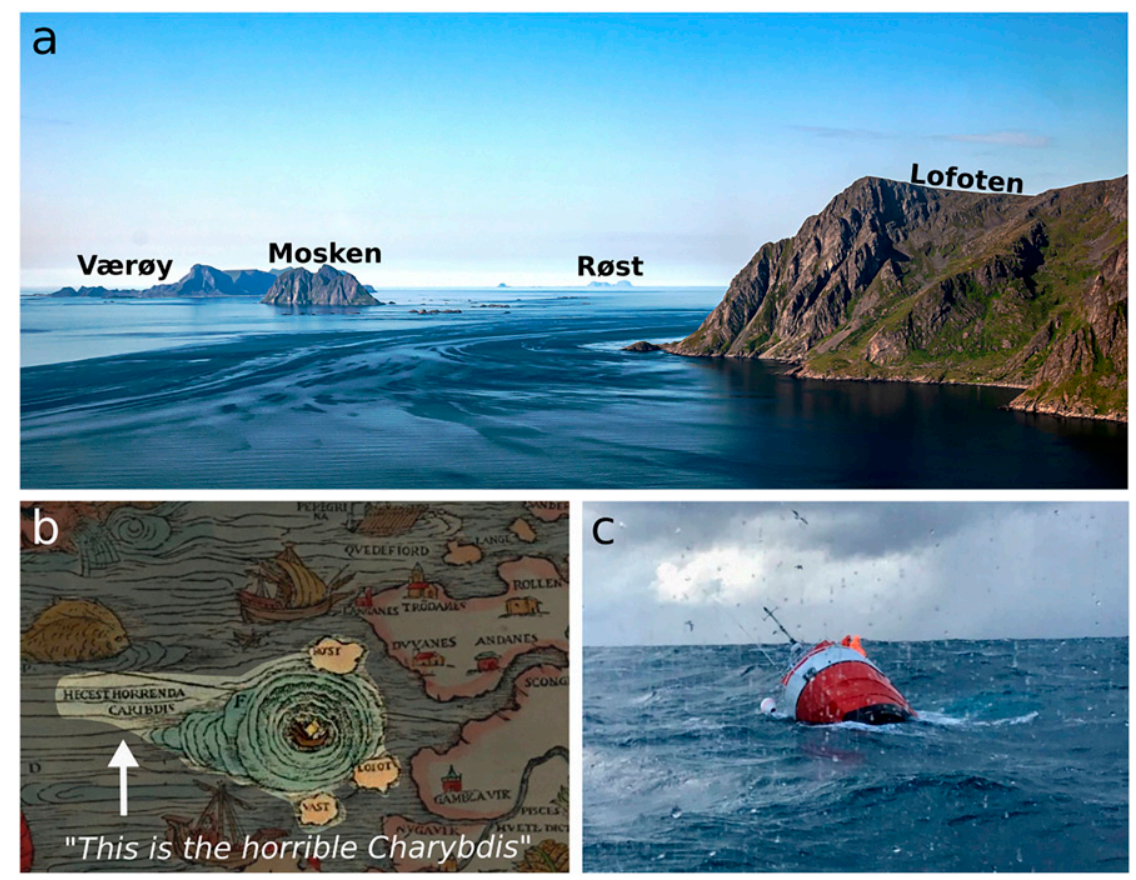

FIG. 1. The many views of Moskstraumen. (a) A photograph of Moskstraumen in the Moskenes Sound from 2009 by Jørn Røssvoll taken from a helicopter. The photograph is most likely taken during a falling tide, as seen from the geometry of the current bending northward around Lofoten. (b) Moskstraumen drawn in "Carta Marina" from 1539 by the Swedish priest Olaus Magnus. Moskstraumen is located in the center of the panel engulfing a ship. (c) The distressed fishing vessel Iselin photographed from a rescue vessel (picture courtesy of the Norwegian Sea Rescue Society). Iselin capsized in the Moskenes Sound in 2017 due to the fishing nets and ropes getting tangled up in the propeller.

conditions which, in turn are affected by the bathymetry, atmospheric and tidal conditions (Masson 1996; Rapizo et al. 2017). At the same time, wave-current interactions are also nonlocal with regards to the current's influence on the waves along their propagation path. This includes current-induced refraction, which is shown to play a key role in modulating the wave field for both swell and wind sea at scales up to several hundreds of kilometers (Gallet and Young 2014; Ardhuin et al. 2017; Romero et al. 2017; Kudryavtsev et al. 2017; Quilfen et al. 2018; Quilfen and Chapron 2019; Villas Bôas et al. 2020; Marechal and Ardhuin 2021). Both Vincent (1979) and Masson (1996) reported that their local observations of significant wave height variability needed to be adjusted for current-induced refraction. In the field studies of Romero et al. (2017), they found that wave breaking at scales $\leq 1 \mathrm{~km}$ was sensitive to the local gradients in the current, but the areas of enhanced wave breaking also overlapped with areas of convergent wave rays. In general, observations reflect cumulative effects as well as local processes.

The aim of this paper is to present the observations of waves and currents in Moskstraumen, shedding some light on dominant interaction processes. The paper is organized as follows. In section 2, we present the governing equations for waves on a variable current together with a simplified expression assessing the importance of the local current gradients on the wave field.
We also present the various data, i.e., observed and modeled, which were used in the analysis. In section 3 , we present the environmental conditions during the case study periods selected from our field campaign. In section 4 we present the results which are further discussed in section 5. Finally, our conclusions are presented in section 6 .

\section{Methods, data, and observations}

\section{a. Governing equations}

\section{1) WAVES ON A VARIABLE CURRENT}

A plane surface wave propagating in a slowly varying medium can be described as

$$
\eta(\mathbf{x}, t)=a e^{i \chi},
$$

where $\chi=\mathbf{k} \cdot \mathbf{x}-\sigma t+\phi$ is the wave phase function. Here, $a, \mathbf{k}$, $\mathbf{x}, \sigma, t$, and $\phi$ denote the wave amplitude, wavenumber vector, horizontal spatial coordinates, angular intrinsic frequency, time coordinate, and random phase, respectively. For waves on a current, the absolute angular frequency is

$$
\omega=\sigma+\mathbf{k} \cdot \mathbf{u},
$$

where $\mathbf{u}=(u, v)$ is the horizontal Eulerian velocity vector representing an ambient current. We thus have 


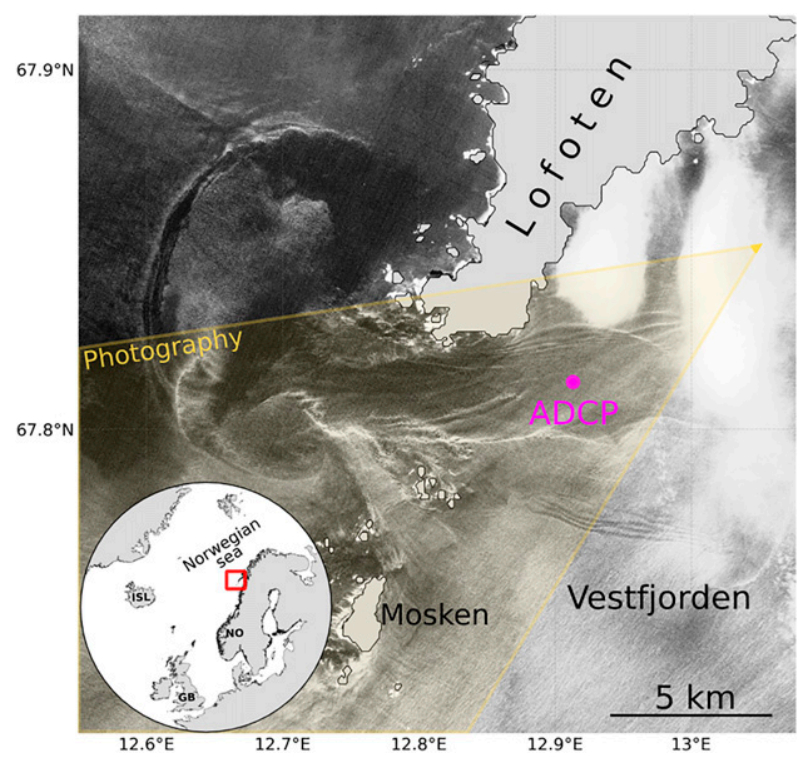

FIG. 2. The area of Moskstraumen. Moskstraumen is located in the Moskenes Sound between Lofoten and the island of Mosken in northern Norway, as indicated by the red square. The sea surface signature of Moskstraumen during a falling tide is captured by the Copernicus Sentinel-2A optical satellite at 21 Jul 2017. The signature is characterized by the plume-like structures west of Lofoten with the narrow white bands indicating areas of breaking waves. The plumes are heading westward. The yellow shaded area and magenta dot shows the area depicted in Fig. 1a and the location of the bottom-mounted ADCP, respectively. Iceland (ISL), Great Britain (GB), and Norway (NO) are marked for reference.

$$
\frac{\partial \mathbf{k}}{\partial t}+\nabla \omega=0
$$

which describes conservation of wave crests within any given area (see, e.g., Phillips 1977, p. 23). The angular intrinsic frequency and wavenumber are related through the general dispersion relation

$$
\sigma^{2}=g \kappa \tanh (\kappa d),
$$

where $d$ is the water depth and $\kappa=|\mathbf{k}|$.

Instead of resolving the phase of each single wave component it is also possible to apply a phase averaging model for the wave energy density $E$, which is common in wave forecasting. Without ambient currents, $E$ is a conserved quantity. But in the presence of currents there is an exchange of energy between the wave field and the mean Eulerian current, and $E$ is no longer conserved (Longuet-Higgins and Stewart 1964). The dynamical aspects of wave evolution could alternatively be formulated as an equation for the wave action, $N=E / \sigma$, which is a conserved quantity in the presence of currents (Bretherton and Garrett 1968; Phillips 1977). From a spectral wave modeling perspective it is common to consider $N=N(t, \mathbf{x}, \kappa, \theta)$, and the evolution of a wave field is modeled through the wave action conservation equation (e.g., WW3DG 2019), here using index notation

$$
\frac{\partial N}{\partial t}+\frac{\partial}{\partial x_{i}}\left(\dot{x}_{i} N\right)+\frac{\partial}{\partial k_{i}}\left(\dot{k_{i}} N\right)+\frac{\partial}{\partial \theta}(\dot{\theta} N)=\frac{\hat{S}}{\sigma} .
$$

Here, $i, j=(1,2)$ represent the horizontal components, and $\theta$ is the direction of the wavenumber vector. The term $\hat{S}$ represents sources and sinks of $E$ like wind forcing and wave breaking in addition to nonlinear interactions. The total time derivative terms (denoted with overdots) constitute the wave ray equations

$$
\begin{aligned}
& \dot{x}_{i}=\frac{\partial \omega_{i}}{\partial k_{i}}, \\
& \dot{k}_{i}=-\frac{\partial \sigma}{\partial d} \frac{\partial d}{\partial s}-k_{i} \frac{\partial u_{i}}{\partial s}, \\
& \dot{\theta}=-\frac{1}{\kappa}\left[\frac{\partial \sigma}{\partial d} \frac{\partial d}{\partial m}-k_{i} \frac{\partial u_{i}}{\partial m}\right],
\end{aligned}
$$

where $s$ is a coordinate in the direction of $\theta$ and $m$ is orthogonal to $s$. In Eq. (5), the terms in Eqs. (6)-(8) represent wave advection by the total group velocity, the evolution in wavenumber, and the change in wave direction, respectively.

\section{2) HORIZONTAL CURRENT GRADIENTS AND WAVE FIELD MODULATION}

Tidal fronts can be considered to be natural laboratories for studying wave-current interactions (Baschek 2005). When considering the processes in the small region with the most intense tidal currents, we chose to disregard the wind forcing in Eq. (5) in order to qualitatively assess the impact of the tides on the wave field. With no wind forcing, the evolution of the wave field would not be realistically represented under conditions with high wind speed. Although the wave field in Moskstraumen is known to become even more complicated under certain weather and wave conditions [see Den norske los (2018) and also the appendix], the spatiotemporal variations in the wind controls scales larger than those by the ocean currents and tides in our area of interest. Thus, local wind wave growth occurs at longer time scales than those associated with the tide (Tolman 1990). Furthermore, we will first disregard the dissipation in the region with most intense tidal currents since we are primarily interested in the period where the tidal currents impact the wave growth, before the waves break. We look more closely at the wave breaking process later on, however, in section 4 . In the following, we turn to the equations for $E$. Wave energy density $E$ is proportional to the square of the significant wave height, and is a common and convenient variable in wave measurements.

Following Phillips [1977, Eq. (3.6.21)], the nondissipative barotropic energy balance equation for waves on a variable current can be written as

$$
\frac{\partial E}{\partial t}+\frac{\partial}{\partial x_{i}}\left(\dot{x}_{i} E\right)+S_{i j} \frac{\partial u_{i}}{\partial x_{j}}=0
$$

where $\dot{x}_{i}=u_{i}+c_{i}^{(g)}$ from Eq. (6), where $c_{i}^{(g)}$ is the intrinsic group velocity. The last term in Eq. (9) is the radiation stress, which denotes the nonlinear transfer of energy between the 


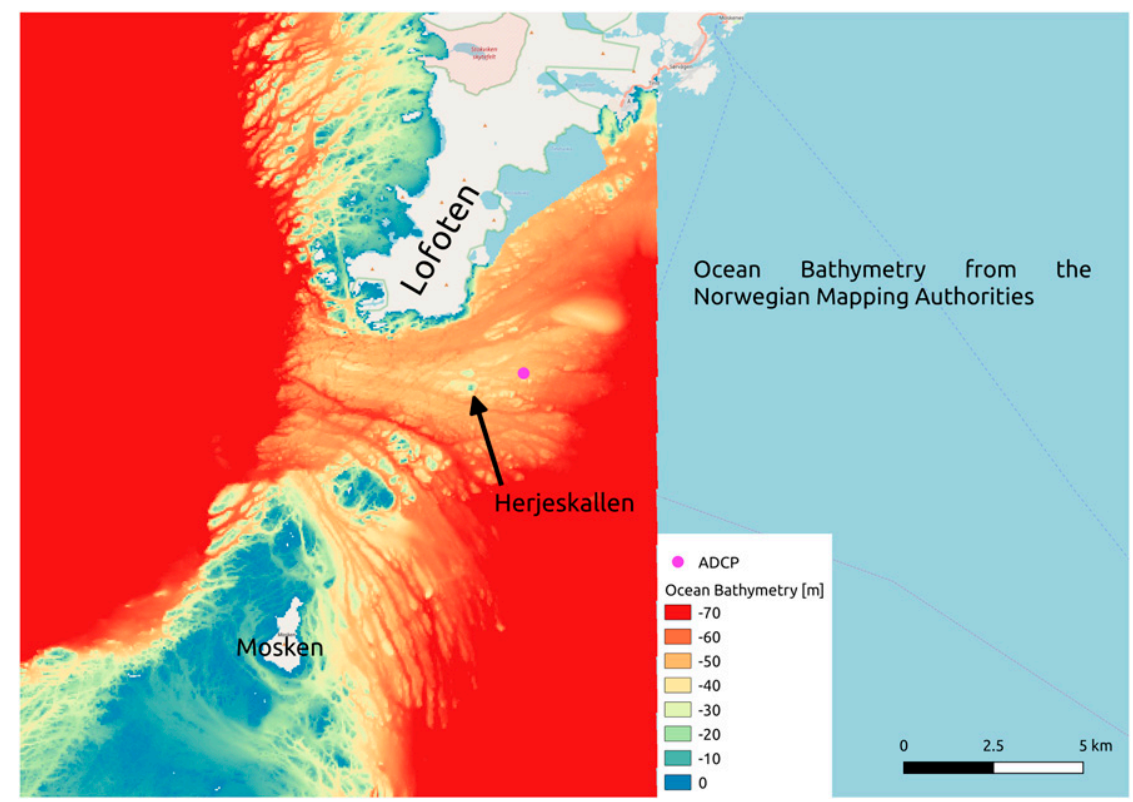

FIG. 3. The bathymetry in the Lofoten area. Red indicates areas with depth $>70 \mathrm{~m}$. The ADCP instrument location is denoted with the magenta dot, located about $2 \mathrm{~km}$ east of the seamount Herjeskallen. The 50-m horizontal resolution bathymetry data are freely available from the Norwegian Mapping Authorities.

waves and the mean Eulerian currents. Equation (9) can be rewritten as

$$
\begin{aligned}
& \frac{\partial E}{\partial t}=-\underbrace{\frac{\partial u_{i}}{\partial x_{i}} E}_{\text {current convergence }}-\underbrace{\frac{\partial c_{i}^{(g)}}{\partial x_{i}} E}_{\text {refraction }} \\
& -\underbrace{\left(u_{i}+c_{i}^{(g)}\right) \frac{\partial E}{\partial x_{i}}}_{\text {wave advection }}-\underbrace{S_{i j} \frac{\partial u_{i}}{\partial x_{j}}}_{\text {radiation stresses }} .
\end{aligned}
$$

The terms on the right-hand side are convergence/divergence of wave energy by the current field, refraction from horizontal gradients in the group velocity due to variations in the water depth or the ambient current, wave energy advection, and the interaction between the radiation stresses and the current gradients.

\section{3) SCALING ARGUMENTS AND TIDAL FORCING ASYMMETRIES}

Lacking direct observations of the horizontal variations, it is difficult to quantify the contribution from each term on the right-hand side in Eq. (10). We do know, however, that the tidal flow is associated with very strong current gradients (see Fig. 2 and later Fig. 9). Since these gradients are primarily due to the geometry of the coastline, bathymetry, and the sharp fronts that develop as the flow entrains the more quiescent regions on both side of the Moskenes Sound, we keep open the possibility that the horizontal length scale $L_{u}$ associated with the tidal flow is different from the horizontal length scale $L_{w}$ of the waves (Tolman 1990). The obvious cases to consider are when the waves and currents are either opposed or aligned.
Opposing wind and currents are known to contribute to significant local wave growth in the Moskenes Sound [see Den norske los (2018) and also the appendix], for which we assume $L_{w}$ and $L_{u}$ are of the same order of magnitude. There is obviously also a modulation of the waves when the waves and currents are heading in the same direction, but reports indicate that the coupling is not as pronounced: the prevailing wave direction is from the southwest, and the waters east of Herjeskallen (Fig. 3) are known to be covered by whitecaps during rising tide, that is, during both calm and rough weather conditions. Heading in the same direction, waves will also increase when the current decelerates. In this case, the decreasing current opposes the waves, relative to its maximum.

Letting $E_{0}, u_{0}, c_{0}$ denote typical values for the wave energy, the speed of the current, and the wave group velocity, respectively, and letting $\beta=c_{0} / u_{0}$, we find that the right-hand side terms of Eq. (10) scale as

$$
u_{0} E_{0}\left[\frac{1}{L_{u}}+\frac{\beta}{L_{w}}+\frac{1}{L_{w}}+\frac{\beta}{L_{w}}+\frac{1}{L_{u}}\right] .
$$

If now $L_{w} / \beta \gg L_{u}$, we see that the first and last terms on the right-hand side of Eq. (10) would dominate. Previous studies suggests that $L_{u}$ decreases in coastal areas due to the influence of the bathymetry (Tolman 1990). In our case, reasonable values are $u_{0}=3 \mathrm{~m} \mathrm{~s}^{-1}$ and $c_{0} \sim 10 \mathrm{~m} \mathrm{~s}^{-1}$, hence $\beta \simeq 3$ and we need to require that $L_{u} \ll L_{w} / 3$. For $L_{u}=10^{2}-10^{3} \mathrm{~m}$ we would require that $L_{w}>O\left(10^{4}\right) \mathrm{m}$, which is only realistic when the waves and currents are aligned. We will analyze this special case in some detail below. 
4) SIMPLIFIED WAVE ENERGY EQUATION FOR ALIGNED WAVES AND CURRENTS

Assuming now that $L_{w} / \beta \gg L_{u}$ holds, we may simplify Eq. (10) such that

$$
\frac{\partial E}{\partial t}=-\frac{\partial u_{i}}{\partial x_{i}} E-S_{i j} \frac{\partial u_{i}}{\partial x_{j}}
$$

If we align the $x$ axis with the wave propagation direction, the nonzero diagonal components of the radiation stress tensor [Phillips 1977, Eq. (3.6.27)] yield

$$
\frac{1}{E} \frac{\partial E}{\partial t}=-\left[\left(2 \frac{c_{g}}{c}+\frac{1}{2}\right) \frac{\partial u}{\partial x}+\left(\frac{c_{g}}{c}+\frac{1}{2}\right) \frac{\partial v}{\partial y}\right],
$$

where $c$ is the phase velocity. The ratio between the phase and group velocity determines the relative weight given to the current gradient components in the $x$ and $y$ directions. Equation (13) gives an impression of how the temporal rate of change of wave energy is related to the horizontal current gradients. The deep water limit allows us to simplify Eq. (13) further,

$$
\frac{1}{E} \frac{\partial E}{\partial t}=-\left(\frac{3}{2} \frac{\partial u}{\partial x}+\frac{\partial v}{\partial y}\right)=-R_{\mathrm{wc}} .
$$

The right-hand side term, excluding the minus sign in front, we denote "relative wave convergence," with the general symbol $R_{\text {wc }}$. At 50-m depth, the mean depth in the Moskenes Sound (Fig. 3), this corresponds to waves with a wavelength of less than approximately $100 \mathrm{~m}(\lambda<2 d)$ with corresponding wave periods from $8 \mathrm{~s}$ and below.

The $R_{\mathrm{wc}}$ is a function of the horizontal current gradients and can easily be computed from an ocean circulation model. Where the current field is convergent, the wave energy will grow. Hence, negative $R_{\mathrm{wc}}$ leads to an increase in energy density, and vice versa where $R_{\mathrm{wc}}>0$. In areas with strong current gradients and barotropic conditions, Eq. (14) can thus provide insight into how the currents modulate the wave field.

\section{b. Observations and model representation of Moskstraumen}

\section{1) ADCP MEASUREMENTS}

Continuous bottom-mounted ADCP measurements were acquired for a 3-month period (6 December 2018-25 February 2019), using a Nortek Signature 500. This is a five-beam instrument capable of measuring currents, waves and turbulence simultaneously. Contrary to traditional ADCPs, the instrument contains a vertically oriented fifth beam, which was used as an echo sounder to both measure distance to the surface and high-resolution backscatter in the water column. The instrument was deployed at the entrance of the Vestfjorden basin as indicated by the magenta dot in Fig. 2, at 50-m depth about $2 \mathrm{~km}$ east of the seamount Herjeskallen (Fig. 3). The instrument was mounted on a tripod in a gimbal to keep it vertically oriented. We used current and wave data from both the averaging mode (averaged values of 60 samples every $10 \mathrm{~min}$ with $1-\mathrm{Hz}$ sample rate and vertical bins of $2 \mathrm{~m}$ ) and burst mode
(17 min sample window with 2-Hz sample rate and 13-min gaps between measurement windows), in addition to the raw altimeter echo burst $(0.0011-\mathrm{Hz}$ sample rate with vertical bins of $2.4 \mathrm{~cm}$ ). Nortek's OceanContour (v. 2.1.2) software was used for processing the data.

Due to the strength of Moskstraumen, in particular during spring tide (i.e., maximum tide during lunar cycle), the instrument tilt sometimes exceeded the limit of what can be compensated by the gimbal. The limit used by Nortek was $10^{\circ}$. For measurements with high tilt, wave data cannot be estimated with sufficient degree of accuracy. Current measurements, however, can be used.

\section{2) ATMOSPHERIC, OCEAN CIRCULATION, AND SPECTRAL WAVE MODEL DATA}

The NORA10 hindcast (Reistad et al. 2011) was used to assess the wind conditions during the field campaign. The horizontal resolution is approximately $10 \mathrm{~km}$, whereas the temporal resolution of the wind field is one hour.

The ocean surface currents were taken from NorKyst800, the Norwegian Meteorological Institute's operational version of the Regional Ocean Modeling System (ROMS; see Shchepetkin and McWilliams 2005). NorKyst800 is a three-dimensional ocean circulation model (hereinafter just referred to as the ocean model) with $800-\mathrm{m}$ horizontal resolution. The vertical dimension is resolved using a terrain-following $\sigma$ coordinate with 35 levels, with higher resolution close to the surface. The uppermost layers have a resolution of approximately $30 \mathrm{~cm}$ in the area of interest. Output fields have a temporal resolution of $1 \mathrm{~h}$. Further specifications of the model setup are given by Albretsen et al. (2011).

A spectral wave model was used to assess the dominating wave conditions outside the area close to the observation site. The estimates are based on the Wave Analysis Model (WAM; Komen et al. 1994). This is an upgraded version of the thirdgeneration WAM code developed under the EU-funded project MyWave (Behrens et al. 2013). The total wave spectrum is made up by the wind sea part and swell, where the wind sea is under influence of the local winds. A common separation of the two regimes is that the wind sea part of the spectrum consists of wave components with phase speed less than the local wind velocity projected onto the wave component direction. Swell is then defined as the remaining part of the spectrum. See Behrens et al. [2013, Eq. (18)] for the exact separation in the WAM model, which also includes the directional difference between the wind and waves.

\section{3) SATEllite observations}

Data from two of the Copernicus Sentinel missions, i.e., Sentinel-1 (S1) and Sentinel-2 (S2), have been used to look for sea surface signatures of wave-current interactions in Moskstraumen. Both missions consist of polar-orbiting satellites with $180^{\circ}$ phase difference. The S1 satellites carry a C-band synthetic aperture radar (SAR) and the S2 satellites carry a Multispectral Instrument (MSI), sampling 13 spectral bands. For S1, we used the high-resolution ground range detected interferometric wide swath mode products with $20 \mathrm{~m} \times 22 \mathrm{~m}$ horizontal resolution (range $\times$ azimuth). For $S 2$, the spectral bands 


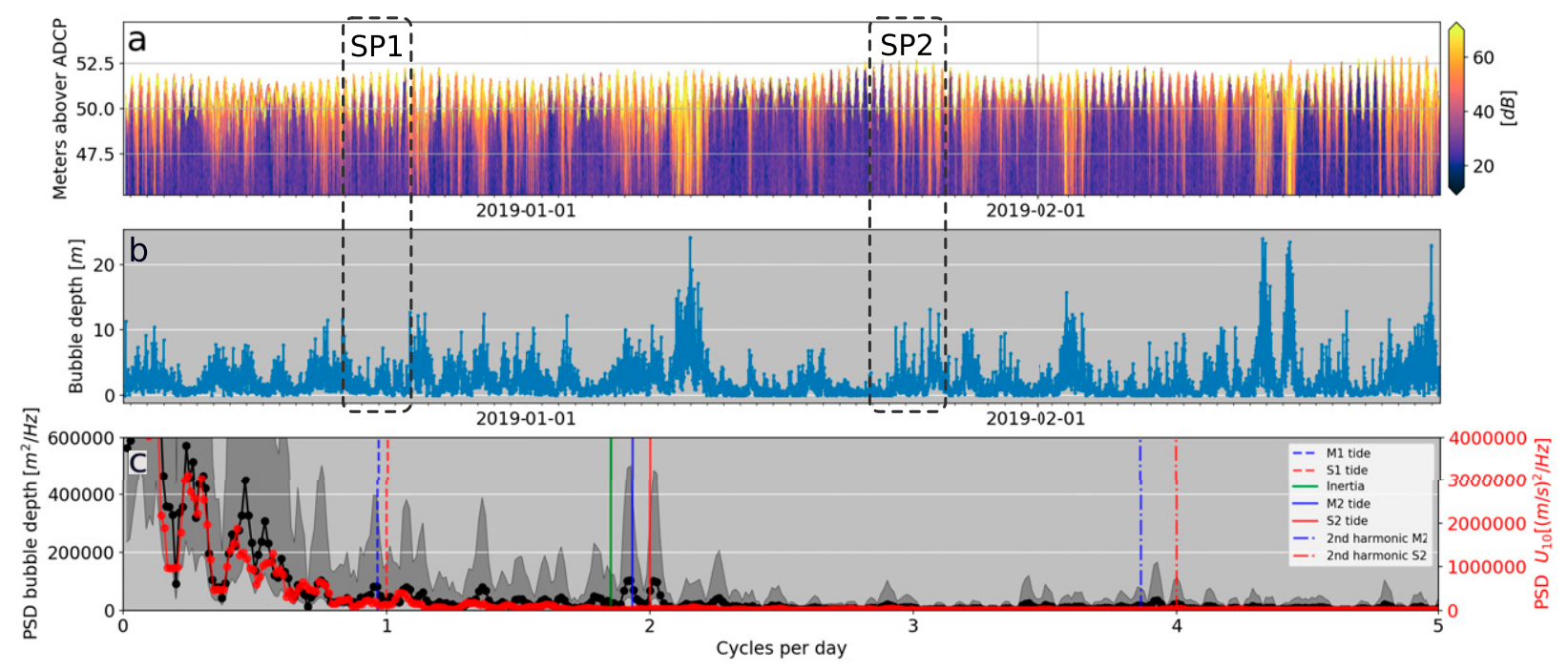

FIG. 4. Computation of approximate bubble depth from the full time series of ADCP measurements together with modeled wind. (a) The smoothed altimeter echo burst $(\mathrm{AB})$ measurements where values above the sea surface are masked out by means of the pressure measurements. (b) The approximate bubble depth computed from the AB measurements and (c) the spectral representation of approximate bubble depth (black line) and $U_{10}$ (red line) for the entire measurement period. The black shaded area denotes the $95 \%$ confidence limit for the bubble depth. SP1 and SP2 denote the case study periods in December 2018 and January 2019, respectively. Frequencies of tidal constituents and the inertial frequency are plotted in the lower panel.

either have $10 \mathrm{~m} \times 10 \mathrm{~m}$ (4 bands), $20 \mathrm{~m} \times 20 \mathrm{~m}(6$ bands $)$, or $60 \mathrm{~m} \times 60 \mathrm{~m}$ (3 bands) horizontal resolution. We used the frequency band B4 with a central wavelength of $664.6 \mathrm{~nm}$. As a consequence of the polar orbits, the temporal resolution for the Lofoten area is quite high, with approximately daily and subdaily coverage for S1 and S2, respectively. However, S2 MSI does not acquire images at low solar angles, which in practice means that there is no coverage in the period from late October until the end of February.

As an illustration of the surface signature of the current at a falling tide, where the flow is directed out of Vestfjorden, we included an optical image (acquired by Sentinel-2A) in Fig. 2. The image clearly shows the strong current gradient on the eastern side (upstream) as well as a plume-like structure on the western side of Moskstraumen, where the outgoing current meets the open ocean.

\section{c. Wave breaking derived from high-resolution raw altimeter echo bursts}

Events of enhanced wave breaking were identified using the raw altimeter echo bursts (hereinafter $\mathrm{AB}$ ) from the ADCP (Fig. 4a). Such measurements can be used as a proxy for wave breaking (Thorpe 1986; Wang et al. 2016; Strand et al. 2020). The data were acquired by an upward-looking echo sounder with a vertical bin resolution of $2.4 \mathrm{~cm}$. From the $\mathrm{AB}$, we estimated a bubble penetration depth in the water column based on signal intensity. We define the bubble depth as the layer between the sea surface and the value from AB exceeding a threshold value, set to $40 \mathrm{~dB}$. All values within the surface layer must exceed the threshold in order to be attributed to wave breaking.

Noise in the AB signal were smoothed column wise using a running mean filter. A time series of the smoothed vertical columns closest to the sea surface is shown in Fig. 4a. Here, values above the sea surface are masked out by means of the pressure measurements. The approximate bubble depth computed from the entire measurement period is shown in Fig. 4b. Outside the spring tide periods of investigation (denoted SP1 and SP2 in Fig. 4), we found that, qualitatively, the bubble penetration depth corresponded well with the wind speed. This was particularly evident during the strongest storms, with a bubble depth of more than $20 \mathrm{~m}$ (Fig. 4b). Moreover, it is possible to separate the six periods of spring tide during the three months measurement period from the envelope of the sea surface height, Fig. 4a.

\section{Weather conditions during the case study periods}

The area surrounding Moskstraumen, or the Lofoten area, is located in an area of prevailing southwesterly winds and waves, particularly during the storm season in fall and winter. In the current work, we focus on two periods during spring tide, i.e., 21-24 December and 22-26 January. These were chosen since they included periods with strong horizontal current gradients, sometimes combined with low wind speeds. Time references refer to UTC time. In the following we provide a brief description of the dominant weather pattern for both periods, which is summarized in Fig. 5.

\section{a. 21-24 December 2018}

At noon 21 December, the synoptic weather situation was dominated by a strong high pressure centered over the Northern Scandinavian peninsula, which, together with a weak low pressure system developing between the Svalbard archipelago and the island of Jan Mayen, directed southerly winds 

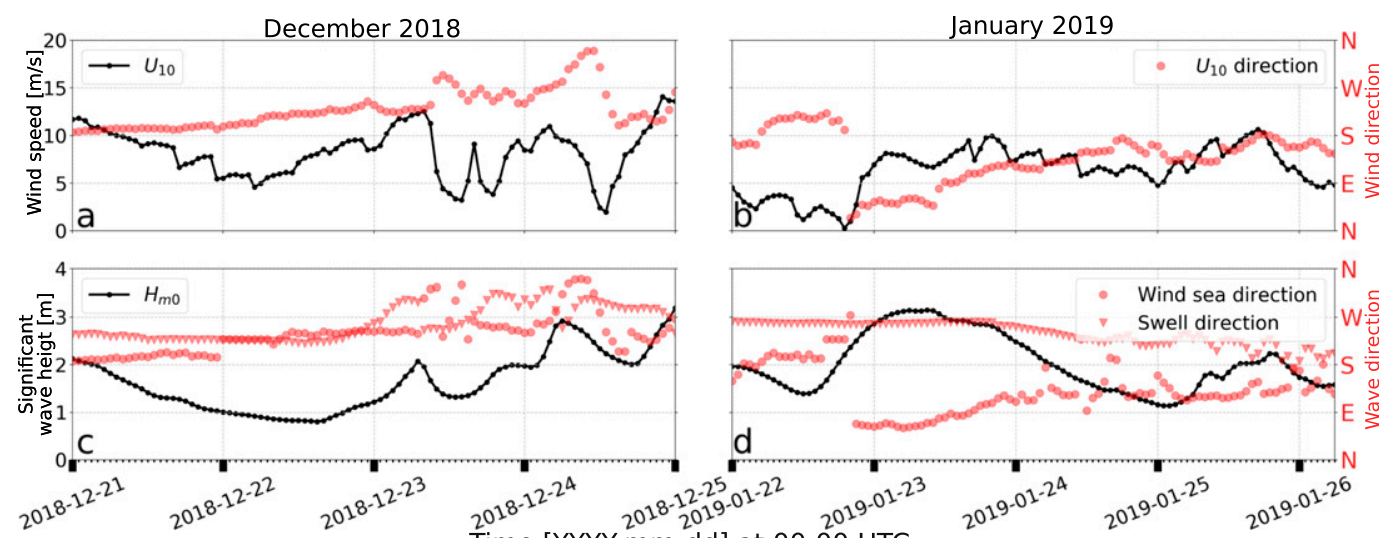

FIG. 5. Time series of the dominant wind and wave conditions during the two periods under consideration. (top) Wind speed at $10 \mathrm{~m}\left(U_{10}\right.$; black) and wind direction (red circles) from a grid point in the NORA10 hindcast close to the ADCP location. (bottom) Significant wave height $\left(H_{m 0}\right.$, black) together with the wave directions (red) from a WAM spectral wave model grid point close to the ADCP location. Wave directions are given for the wind sea regime (circle) and swell (triangle), where wind sea and swell are discriminated by a criterion based on the directional difference between wind and wave propagation as well as the inverse wave age. All directions follow the meteorological convention (coming from). $\mathrm{N}$, E, S, and W denote north, east, south, and west, respectively.

over Moskstraumen (Fig. 5a). During 22 December the wind turned southwesterly, increasing in strength. On 24 December the synoptic weather situation was dominated by a rather intense low pressure system coming from the west/southwest. As this low approached the Norwegian coast, the wind speed increased to about $14 \mathrm{~m} \mathrm{~s}^{-1}$ in the late evening. The significant wave height was less than $3 \mathrm{~m}$ during the entire period (Fig. $5 \mathrm{c}$ ). The wind sea and swell were mainly headed eastward.

\section{b. 22-26 January 2019}

On 22 January a weak high pressure ridge was located over the Lofoten peninsula, resulting in weak southerly winds (less than $5 \mathrm{~m} \mathrm{~s}^{-1}$ ) and significant wave heights below $2 \mathrm{~m}$ (Figs. $5 \mathrm{~b}, \mathrm{~d}$ ). During the evening, a high pressure system built up over the Svalbard archipelago, while at the same time a more intense low pressure system came in from the southwest near Iceland. This resulted in a change to northeasterly winds at the observation site and steadily increasing wind speed. The large-scale wind pattern remained stationary for the rest of the study period, with the observation site located between these two synoptic systems.

\section{Results}

\section{a. Current maxima}

For the 3-month period of the ADCP deployment at the seabed in Moskstraumen, we measured current speeds up to $3 \mathrm{~m} \mathrm{~s}^{-1}$ at $10-\mathrm{m}$ depth, confirming previous model studies (Gjevik et al. 1997; Moe et al. 2002; Ommundsen 2002). Due to the instrument's location, we do not expect this to represent the maximum strength of the tidal current, which is more likely to be found where the Moskenes Sound is at its narrowest.

\section{b. Wind, waves, and enhanced wave breaking}

There is a connection between the observed bubble depth and the modeled wind (Figs. 5 and 6). The wind affected the wave energy density spectrum and the bubble depth measurements in terms of both its strength and direction. This was particularly evident during the second part of January 2019. Here, the wind had shifted from heading east and northward to more westward (about 2000 UTC 22 January, Fig. 5b). It also ramped up in strength. The impact on the wave energy spectrum was a transition to a wider spectrum. This is seen at 2000 UTC 22 January and 1000 UTC 25 January with more energy on neighboring frequencies around $0.1 \mathrm{~Hz}$ and $0.2 \mathrm{~Hz}$, respectively (Fig. 6d). Considering the $\mathrm{AB}$, the sea surface got rougher, indicating enhanced wave breaking during larger portions of the period, in particular from 1000 UTC 25 January to 0000 UTC 26 January (Fig. 6b).

To compare the wind speed with enhanced wave breaking (or bubble depth), we performed a power spectral density (PSD) analysis on both these variables for the entire measurement period (Fig. 4c). Here we found that the low frequencies in the PSDs fitted well with the passage of synoptic weather systems. That is, from zero and up to about 0.75 cycles per day. For lower frequencies, the wind speed signal dropped close to zero while the enhanced wave breaking had spikes close to those of the semidiurnal tidal constituents, $M_{2}$ and $S_{2}$.

\section{c. Wave breaking during a rising tide}

The time series of relative wave convergence $R_{\mathrm{wc}}$, computed from the ocean model at the ADCP location, are presented in Figs. 7a and 7e. Both panels consistently show negative wave convergence for approximately 3 -hourly periods before pronounced peaks in the surface tracker signal from the ADCP (Figs. 7b,f). The peaks indicate enhanced wave breaking and are marked with gray vertical bars. Moreover, the enhanced wave breaking corresponded with the maximum current speed (Figs. 7c,g). This was further supported by the spectral representation of wave breaking during all spring tide situations in our ADCP data (Fig. 8). Here we found good agreement 

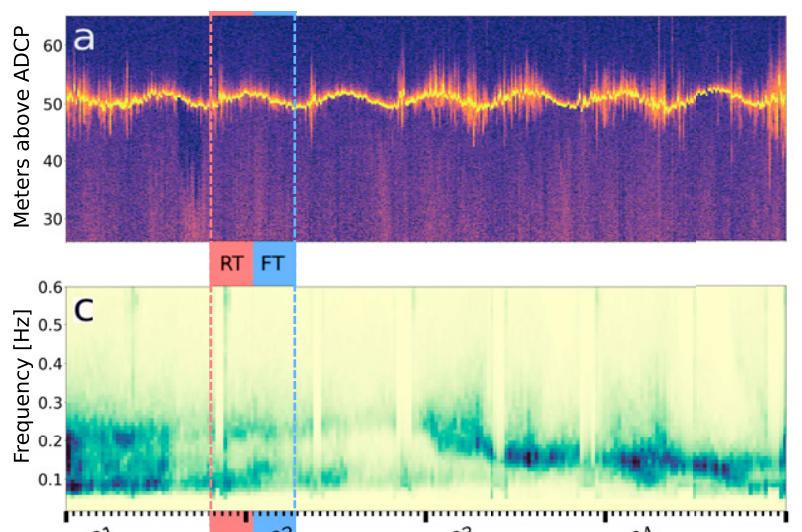
$2018-22-21 \quad 2018-12-$ $2018-12-23$ $2018-12-24$

Time [YYYY-mm-dd] at 00:00 UTC
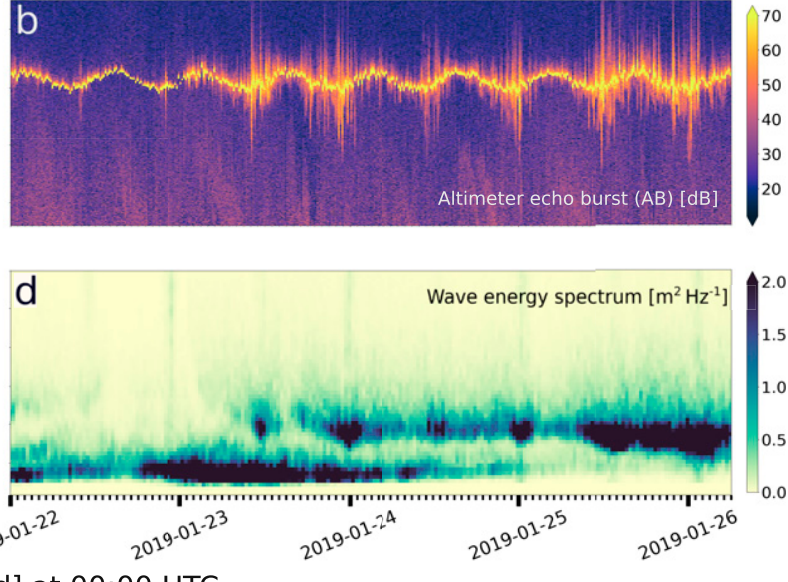

FIG. 6. Time series of altimeter echo burst $(\mathrm{AB})$ and wave energy spectrum during the study periods from the ADCP measurements. (a),(b) AB inverse echo sounder signal from the ADCP. (c),(d) The wave energy spectrum from December 2018 and January 2019 , respectively. The red and blue areas approximately show the phases of a rising tide (RT) and a falling tide (FT), respectively. At the location of the ADCP, the currents shift direction from eastward to westward during RT. During FT, the currents shift direction from westward to eastward. RT is also characterized with maximum current speed which corresponds with the spikes in the AB signal during RT.

between bubble depth and the $\mathrm{M}_{1}, \mathrm{~S}_{1}$, and $\mathrm{S}_{2}$ tidal frequencies, and in particular the $\mathrm{M}_{2}$ constituent. The inertial frequency is close to the $\mathrm{M}_{2}$ frequency in the Lofoten area. All these events happened at a rising tide, which means that the tidal flow was directed eastward into Vestfjorden (right panels, Fig. 9). The current speed shows an almost uniform vertical profile, confirming the assumption of predominantly barotropic conditions in Eq. (9).

The degree of alignment between the Eulerian current and mean wave direction is shown in Figs. $7 d$ and 7 h. Here, the directions are projected on to one another, with values of unity indicating that the current is headed in the mean wave propagation direction and going against for negative values. In December 2018 (left panel, Fig. 7), we found repeated events of enhanced wave breaking when the flow was in the direction of the waves at current maximum. This period was characterized by winds mostly below $10 \mathrm{~m} \mathrm{~s}^{-1}$ and a steady propagation of swell from the west (Figs. 5a,c). Likewise, in the beginning of January 2019, waves would also break when propagating in the direction of the current during current maxima (see between
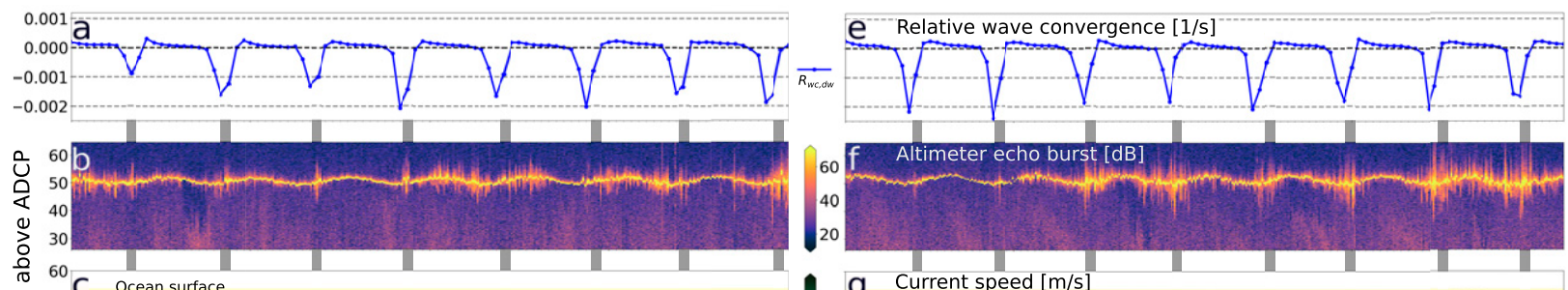

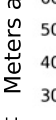
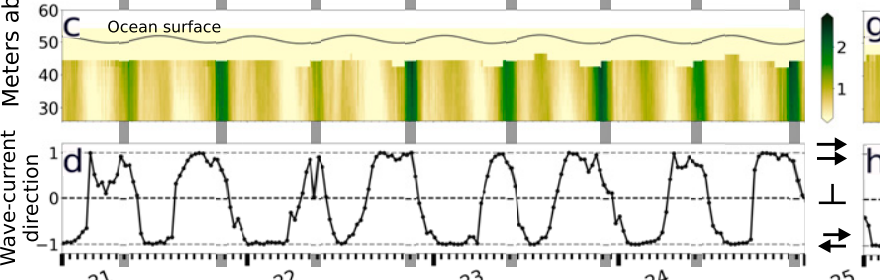

$2018-12.21 \quad 2018-12-22$

$2018-12-23$

$2018-12-24$

$2018-12-25019-01-22$

Time [YYYY-mm-dd] at 00:00 UTC

FIG. 7. Time series of wave and current properties for the two study periods. (a),(e) Relative wave convergence, $R_{\mathrm{wc}, \mathrm{dw}}$, computed from the ocean model. (b),(f) Altimeter echo burst (AB) data from ADCP. (c),(g) Vertical profile of current speed from ADCP and the sea surface from bottom pressure measurements. (d),(h) Projected wave and current direction where values 1,0 , and -1 denote same, orthogonal, and opposite direction for wave propagation and currents, respectively. Vertical gray bars indicate periods of max current speeds at the rising tide. 


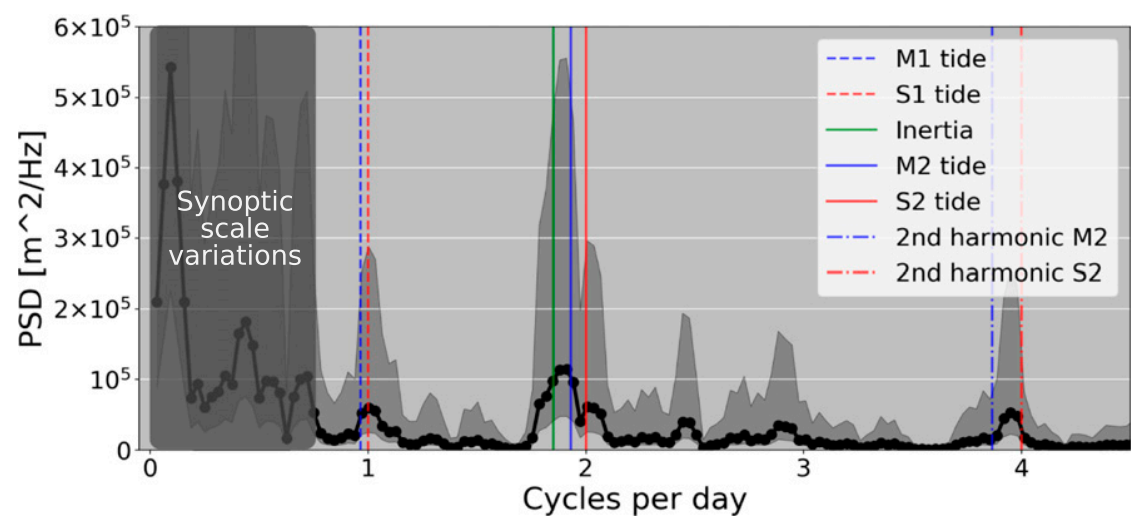

FIG. 8. Power spectral density of approximate bubble depth (black line) during spring tide situations from the ADCP measurements. The black shaded region around the PSD denotes the $95 \%$ confidence limit. The spectral representation shows increased wave breaking, which coincides with the frequency of the tidal constituents, in particular $\mathrm{M}_{2}$, $\mathrm{S}_{2}$, and the inertial. These frequencies correspond to the maximum current speed in Moskstraumen. The synoptic-scale variations in $U_{10}$ coincide with wave breaking from zero up to approximately 0.75 cycles per day as seen in Fig. $4 c$.

0000 UTC 22 January and 1200 UTC 23 January in Figs. 7f-h). When the wind turned northwesterly and ramped up (around 0300 UTC 23 January, Fig. 5b), we ultimately observe a shift to higher frequencies in the wave energy spectrum (Fig. 6d). We also observe a general increase in wave breaking, mostly before and during current maxima (see between 1200 UTC 23 January and 0000 UTC 24 January in Figs. 7f,g). From 1200 UTC 24 January and out, the waves were opposing the current to a larger degree, including current during maxima (see 1200 UTC 25 January in
Figs. 7f,h). This period was also characterized with enhanced wave breaking, still containing spikes around the current maxima.

\section{d. Moskstraumen from ocean model, satellite observations, and $A D C P$}

Figure 9 illustrates the sea surface signature of Moskstraumen at falling and rising tides. A falling tide is characterized by white narrow bands forming plume-like structures west of Lofoten in the optical S2 image (bottom left), and a wider white shaded area in the

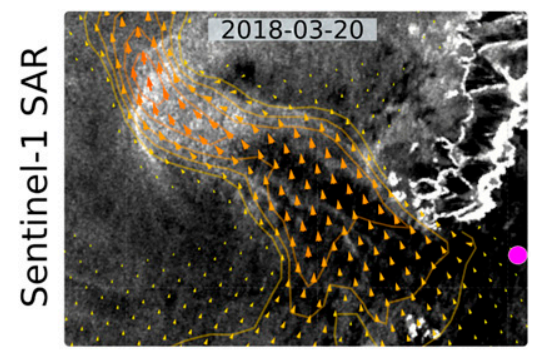

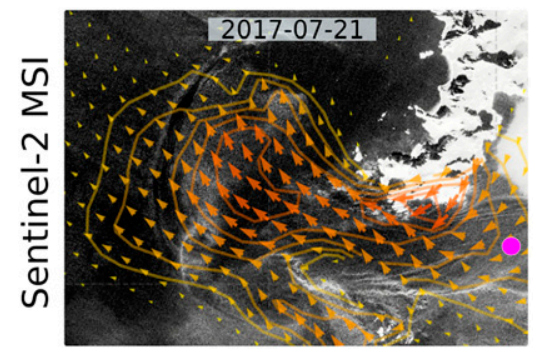

Falling tide
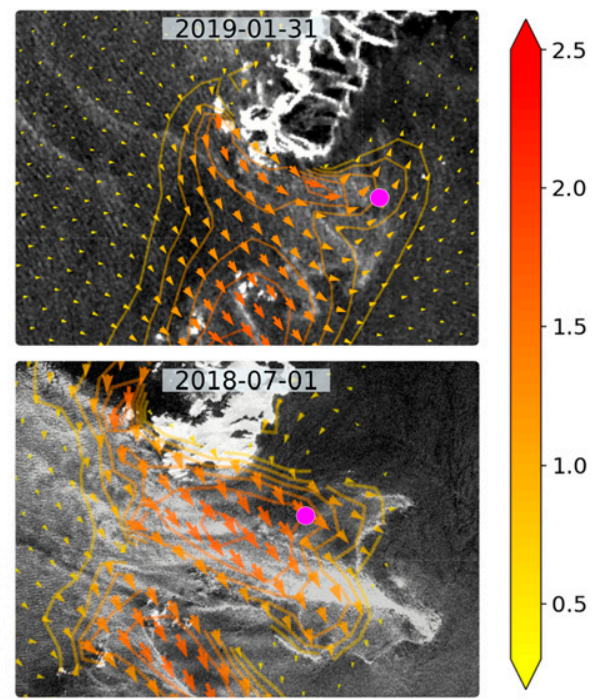

Rising tide

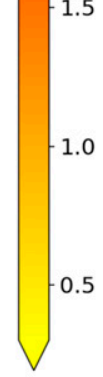

$[\mathrm{m} / \mathrm{s}]$

FIG. 9. Satellite and ocean model representation of Moskstraumen. Satellite imagery of Moskstraumen at (left) a falling tide and (right) a rising tide with modeled ocean surface currents overlaid. The satellite images in the top and bottom panels are from the Copernicus Sentinel-1 and Sentinel-2 missions, respectively. The magenta dot indicates the position of the bottom-mounted ADCP. The dates of the events are denoted in each of the images. The image in the top-right panel was taken during the ADCP deployment. The time difference between satellite acquisition and model time was within $30 \mathrm{~min}$ for all the cases. 


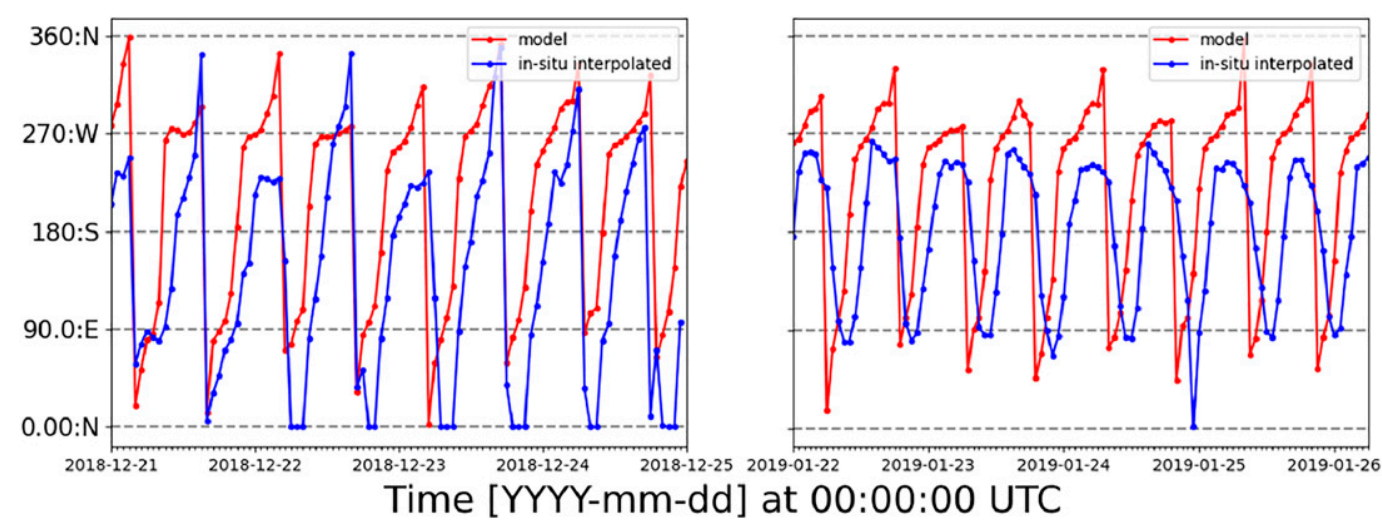

FIG. 10. Time series comparing the ocean current direction between the ocean model and the ADCP measurements for the two study periods. N, E, S, and W denote north, east, south, and west, respectively. The red line shows output from the ocean model interpolated to the location of the ADCP. The blue line shows the ADCP measurements interpolated to the temporal resolution of the ocean model. Direction here denotes where the current is heading to.

S1 SAR image (top left), both indicating zones of wave breaking (Kudryavtsev et al. 2005, 2017). The situations during a rising tide (right panels in Fig. 9) shows similar structures, but now the tidal current flow into Vestfjorden. We have overlaid the modeled surface currents on the satellite images in Fig. 9. The horizontal structure of the tidal flow appears to be well represented by the model.

Figure 10 compares the modeled ocean current with the ADCP measurements. The modeled currents were interpolated to the measurement location and the ADCP measurements were linearly interpolated to the temporal resolution of the model. Despite an overall satisfactory agreement between the two, there were differences in both the gradients of the current direction (i.e., the turning rate) and the phase. This is unsurprising given a model resolution of $800 \mathrm{~m}$. The difference in time and direction was generally less than $2 \mathrm{~h}$ and $90^{\circ}$, respectively.

In Eq. (14), we are primarily interested in the duration of the periods of positive and negative relative wave convergence, and not necessarily the magnitude. These periods were estimated to last 4-5 h (Fig. 7). Hence, the discrepancies in terms of the direction and its phase between the model and the ADCP data were within the limits which we considered to be satisfactory for the time scales considered here.

\section{e. Current gradients}

The modeled horizontal current divergence, $\delta=\partial u / \partial x+\partial v / \partial y$, and the vertical vorticity $\zeta=\partial v / \partial x-\partial u / \partial y$ were computed for the area surrounding Lofoten. An example during a rising tide is shown in Fig. 11, where the divergence and vorticity are normalized by the inertial or Coriolis frequency $f$. During all the rising tide situations in the two study periods, the location and horizontal extent of the divergent and convergent areas in the Moskenes Sound were consistent with what is shown in Figs. 11d and 11e. That is, the tidal current formed two eddies, the northernmost located just east of the Lofoten peninsula, rotating counterclockwise, and the southernmost just east of Mosken, rotating clockwise (see the relative vorticity plot in Fig. 11e). As the current turned with the tide, the northernmost eddy disappeared while the southernmost eddy was advected out of the Moskstraumen branch before dissipating in Vestfjorden (not shown). The main structures in Moskstraumen resolved by the ocean model during a rising tide are in accordance with earlier studies by Lynge (2011).

Recent studies show that the current's vertical vorticity plays a key role in modifying several properties of the wave field like peak period, direction and significant wave height (e.g., Gallet and Young 2014; Quilfen et al. 2018; Quilfen and Chapron 2019). In idealized experiments, Villas Bôas et al. (2020) showed that refraction was the main mechanism leading to gradients in significant wave height, and that the effect of divergence was significantly smaller, even when adding an energetic divergent flow to a purely rotational one. Moreover, Villas Bôas and Young (2020) derived an expression for wave action diffusivity showing that the diffusivity was only a function of the rotational part of the current to first order. This is in accordance with the result showing that the curvature of a wave ray can be computed from the ratio between the vorticity and the group velocity

$$
\chi_{\mathrm{rc}}=\zeta / c_{g},
$$

assuming $\delta_{\mathrm{cu}}=|\mathbf{u}| / c_{g}$ is small. The term $\chi_{\mathrm{rc}}$ is the wave ray curvature $\left(\mathrm{m}^{-1}\right)$ (Kenyon 1971; Dysthe 2001).

In the area west and southwest of the Moskenes Sound, there were several regions with $\zeta$ of the same order as $f$, as seen in Fig. 11b. This was the case for both the study periods (not shown). The location of these regions varies with the flow and was in general advected northward by the Norwegian coastal current. To investigate the impact from current-induced refraction, we performed a simple ray-tracing analysis solving Eqs. (6)-(8) numerically. Figure 12a show the effect of refraction for an in incoming $7 \mathrm{~s}$ period long crested wave when exposed to the current field in Fig. 11c. The initial wave propagating direction $\alpha_{\mathrm{in}, 0}$ was chosen according to values from the spectral wave model. In this case the Moskenes Sound was subject to diverging wave rays. Wave ray paths are, however, sensitive to their initial direction as well as to the location of areas with strong $\zeta$ (Masson 1996). To assess the sensitivity with respect to the initial propagation direction, we computed the wave ray density from perturbing the incoming wave direction, which we denote $\alpha_{\text {in, },}$. The area in Fig. 12a was further divided into grid boxes with size 5 times the grid resolution of the ocean model, 

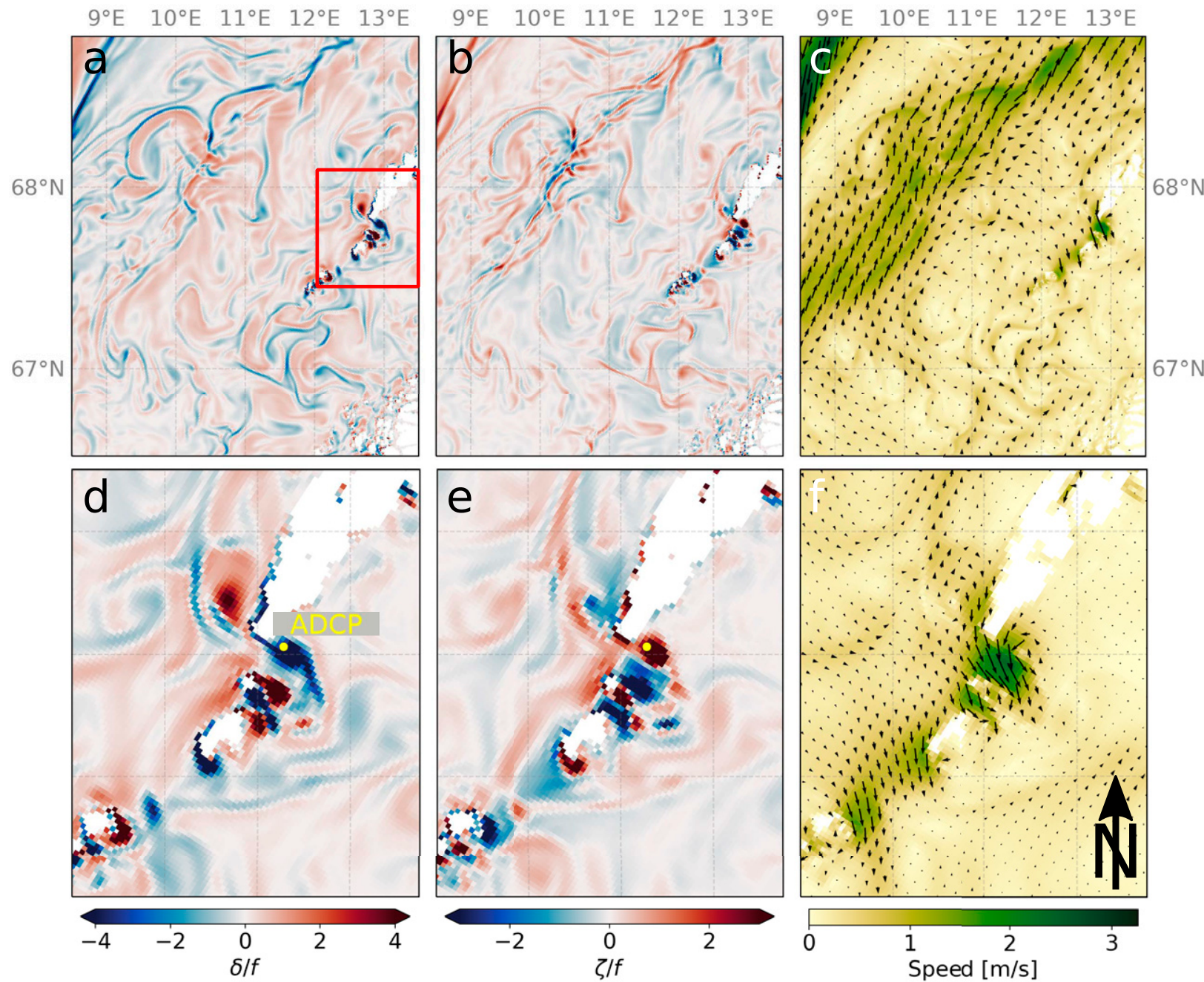

FIG. 11. An overview of the horizontal surface current gradients and speed at 2200 UTC 22 Jan 2019 during a rising tide computed from the ocean model showing the (a),(d) current divergence; (b),(e) vertical vorticity; and (c),(f) current velocity vectors overlaid the current speed. Divergence and vorticity are scaled by the inertial frequency. (top) The large-scale situation and (bottom) a zoom in on the area of interest covering the red square in (a). The yellow dot denotes the ADCP instrument location.

for which the wave ray density was computed for each grid box. The ray density is the ratio between the average number of wave rays for all realizations within the grid box and the number of incoming wave rays in the initial grid boxes, i.e., before refraction due to currents had happened. The wave ray density could be considered an indicator for wave energy, with dense areas having larger energy due to crossing waves (Rapizo et al. 2014). Figure 12b show the spatial distribution of wave ray density for five realizations of the 7 -s period wave, i.e., four $2.5^{\circ}$ directional increments around $\alpha_{\mathrm{in}, 0}$ including the result for $\alpha_{\mathrm{in}, 0}$. From the computation, the Moskenes sound was not exposed to focusing wave rays with wave ray density just below one.

\section{f. Evolution and horizontal extent of relative wave convergence}

Temporal evolution of relative wave convergence $R_{\mathrm{wc}}$ and $\zeta$ in the Moskenes Sound are presented in Fig. 13. Note that $R_{\mathrm{wc}}$ was computed with the $x$ axis taken as the direction of wave propagation as in Eq. (14), implying waves coming from west. The areas of strong $\zeta$ and $R_{\mathrm{wc}}$ were collocated in space and time, in particular for the two cyclonic and anticyclonic eddies in the Moskenes Sound described above. The extent of the area with negative $R_{\mathrm{wc}}$ covering the ADCP was growing steadily from 2000 UTC 22 January (Fig. 13a) until 2200 UTC 22 January (Fig. 13c), with the latter being the time when enhanced wave breaking and maximum current speed was measured by the ADCP (Figs. 7f,g). At this point, the area had the shape of an ellipse with minor and major axes of approximately $5 \mathrm{~km}$ in north-south direction and $10 \mathrm{~km}$ in east-west direction, respectively. The location and extent of $R_{\mathrm{wc}}$ and $\zeta$ was about the same throughout January 2019 (not shown).

\section{Discussion}

\section{a. Estimating the effect of relative wave convergence}

According to Eq. (14), the wave energy density is expected to grow steadily during periods of negative wave convergence. 

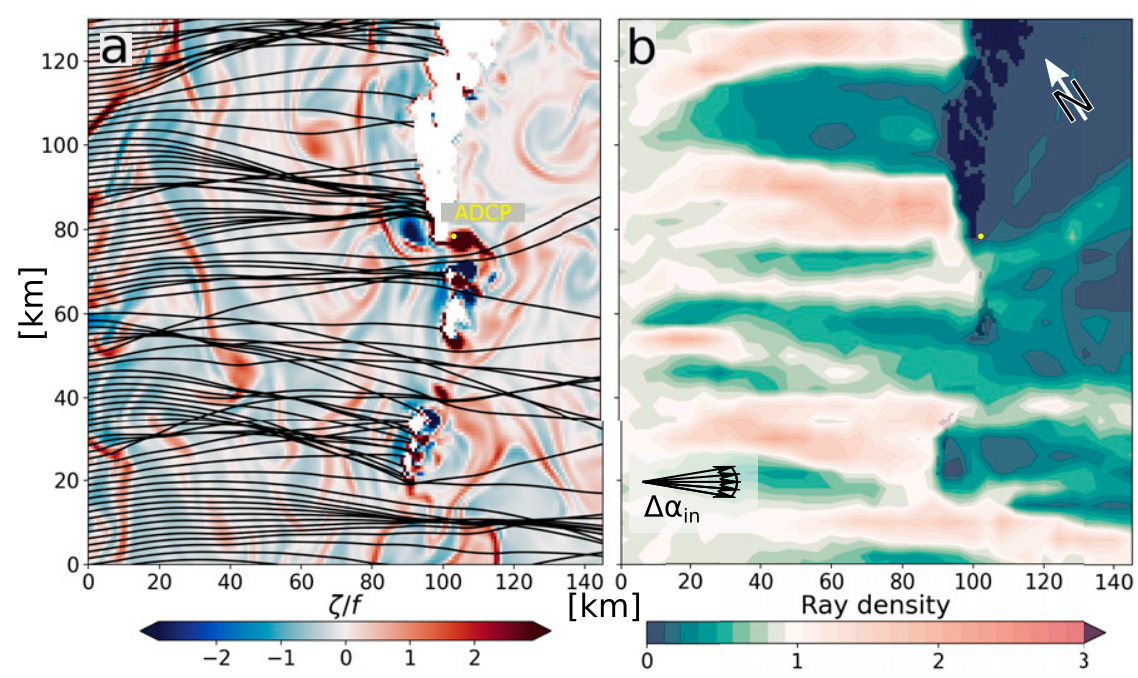

FIG. 12. Temporal evolution of wave rays from solving the wave ray equations for the current velocity field in Fig. 11c. (a) The evolution for a long crested 7-s period wave with initial propagation direction according to the WAM model. The wave rays are overlaid the vorticity field. (b) The density of wave rays computed from five realizations of the same wave in (a), but with five different initial propagation directions, i.e., waves with directional increments, $\Delta \alpha_{\text {in }}$, of $2.5^{\circ}$ around the central initial propagation direction, as shown in (a). The directional increments are exaggerated for illustration purposes. The "ray density" is computed for grid boxes with size of $5 \times 5$ the grid resolution of the ocean model and is the ratio between the average number of wave rays for all realizations and the initial number of rays in the incoming grid boxes.

This means that energy accumulates in the wave field, leading to a net increase in wave height. A first-order estimate on the effect of relative wave convergence can be made by discretizing Eq. (14),

$$
\frac{1}{E_{k}} \frac{E_{i+1}-E_{i}}{\Delta t}=-R_{\mathrm{wc}} .
$$

Here $i$ denotes the discrete time levels $\Delta t=t_{i+1}-t_{i}$. Temporal modulation of $E$ due to $R_{\mathrm{wc}}$ is then obtained by rewriting the expression as

$$
E_{i+1}=E_{i}-\Delta t E_{i} R_{\mathrm{wc}} .
$$

Equation (17) was solved for a range of representative $R_{\mathrm{wc}}$ values computed from the ocean model. Figure 14 show the isolated effect of $R_{\mathrm{wc}}$ on the wave energy density in a wave field with initial value $E_{0}=1$. Figure 14 b show two examples of how the wave energy density changes for waves propagating a representative distance of $10 \mathrm{~km}$ with varying $R_{\mathrm{wc}}$ (Figs. $13 \mathrm{a}-$ d). The 7 -s period wave $\left(c_{g}=5.5 \mathrm{~m} \mathrm{~s}^{-1}\right)$ propagates $10 \mathrm{~km}$ in approximately $30 \mathrm{~min}$. While propagating, the wave group experiences varying $R_{\mathrm{wc}}$, and the resulting maximum positive change in wave energy density is $\Delta_{E, \max }=E_{\max }-E_{0} \simeq$ $3 \mathrm{~m}^{2} \mathrm{~Hz}^{-1}$ (dashed line, duration $=25 \mathrm{~min}$ in Fig. 14b). The $5 \mathrm{~s}$ period wave $\left(c_{g}=3.9 \mathrm{~ms}^{-1}\right)$ propagates the distance in approximately $43 \mathrm{~min}$, with a resulting $\Delta_{E, \max } \simeq 4.5 \mathrm{~m}^{2} \mathrm{~Hz}^{-1}$ (solid line, duration $=35 \mathrm{~min}$ in Fig. 14b).

Longer waves approaching the shallow water limit would also be modulated according to Eq. (17), using the shallow water solution of Eq. (13). The group velocity for shallow water waves would be larger than $22 \mathrm{~m} \mathrm{~s}^{-1}$ in the area of interest, which means they would propagate a distance of $10 \mathrm{~km}$ in less than $8 \mathrm{~min}$. Even if the relative weight of the current gradients is larger for the shallow water solution than for deep water, the propagation speed limits the wave growth being bounded by the extent of the area with strong current gradients.

Relative wave convergence of $O\left(10^{-3}\right) \mathrm{s}^{-1}$ produces the same effect as current gradients of $O\left(10^{-1}\right) \mathrm{s}^{-1}$. We expect the current gradients in Moskstraumen to be higher for certain periods, in particular during spring tide, and capable of modulating the wave field according to Eq. (17). However, smallscale variability in the currents not resolved by the model could cause directional changes in the mean current for certain areas. The areas of convergent and divergent currents change accordingly, which in turn affects $R_{\mathrm{wc}}$. In addition, if a wave is not propagating in the positive $x$ direction, the cross terms in the radiation stress tensor (12) becomes nonzero and the contribution from each of the horizontal current gradient terms in Eq. (13) changes accordingly. This would again affect $R_{\text {wc }}$. Another important aspect is that Eq. (14) does not take dissipation through wave breaking into account nor input of energy from the wind, which obviously is present in our measurements (Figs. 7b,f).

Another interesting feature is the observation that the minimum relative wave convergence occurs halfway during the period of negative wave convergence (top panel, Fig. 7). One might expect the maximum growth rate to be associated with enhanced wave breaking. It is, however, the horizontal extent of the current gradients that is important for the waves to "feel" the effect of the current over a sufficiently long period. 


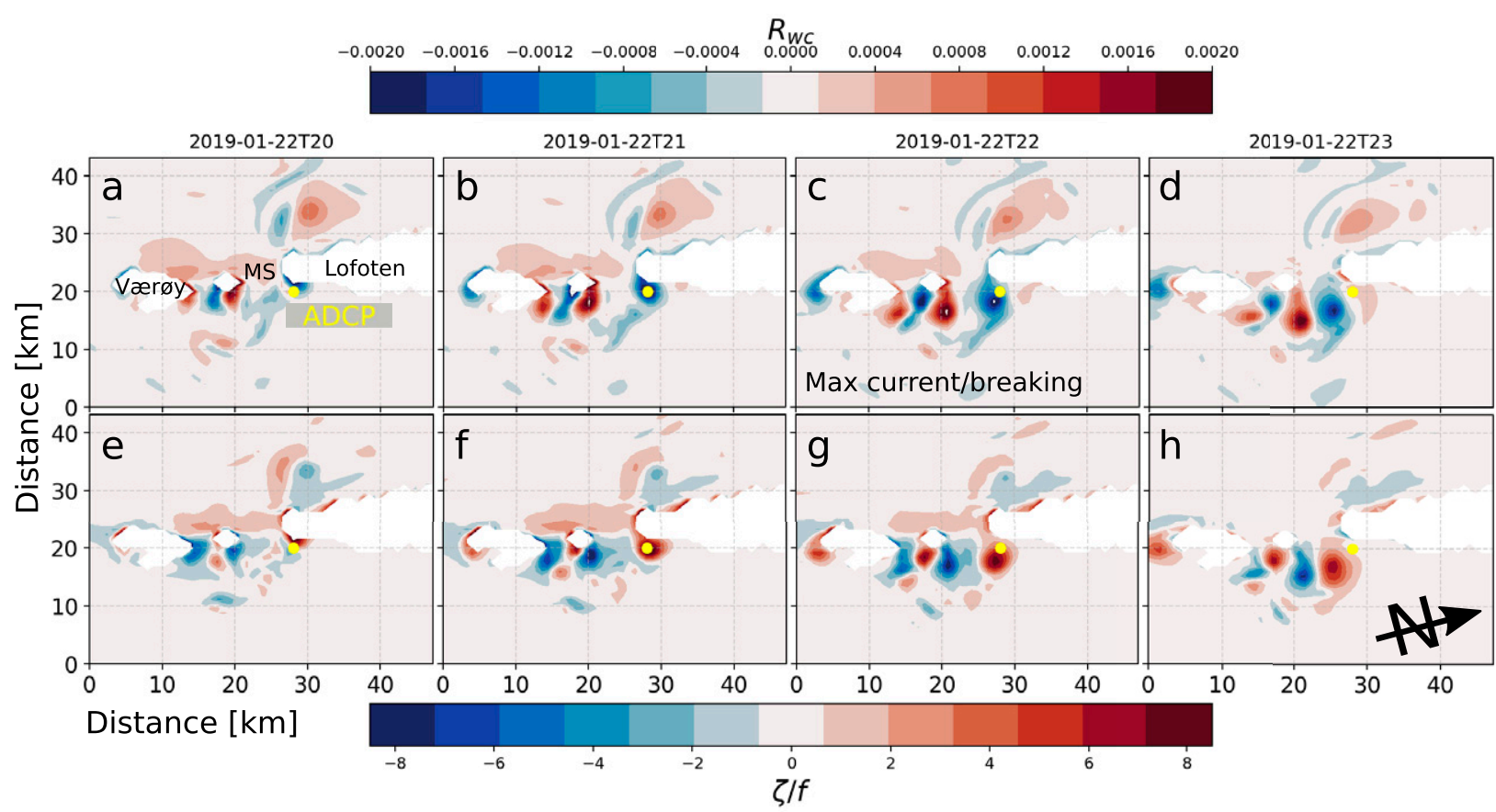

FIG. 13. The development of areas of relative wave convergence $R_{\mathrm{wc}}$ and normalized vertical vorticity $\zeta / f$ during a rising tide in Moskstraumen. The $R_{\mathrm{wc}}$ was computed with the $x$ axis taken as the direction of wave propagation as in Eq. (14), implying waves coming from west. The island of Værøy and the southern tip of the Lofoten Penisula are shown in (a). "MS" denotes the Moskenes Sound. The location of the ADCP is indicated by the yellow dot.

As long as the relative wave convergence is negative, the waves will continue to grow despite a decrease in magnitude. This is clearly seen in Fig. $14 \mathrm{~b}$ where $E=E_{\max }$ occurs long after $R_{\mathrm{wc}}(t)=R_{\mathrm{wc}, \min }$.

\section{b. Wave-current interactions and wave breaking}

From the observations, enhanced wave breaking systematically occurred during a period of negative wave convergence $\left(R_{\mathrm{wc}}<0\right.$, see Figs. 7a,b,e,f), and coincided with the current maximum (Figs. 7c,g). From a spectral analysis, we found a good correspondence between the enhanced wave breaking and the semidiurnal tidal constituents $\mathrm{M}_{2}$ and $\mathrm{S}_{2}$ (Figs. $4 \mathrm{c}$ and 8). This was consistent during periods with wind speeds well below $10 \mathrm{~m} \mathrm{~s}^{-1}$ with steady swell from the west, but also in periods with higher wind speeds and local wind sea propagating eastward, like at the end of January 2019 (Figs. 5b,d).

Enhanced wave breaking also happened when the currents and waves were heading in the same direction (e.g., Fig. 7d). Wave breaking is related to steepening of waves, and thus to a modulation in wave amplitude and/or wavenumber. Several works have reported an increase in wave heights for waves and currents that are heading in the same direction (Vincent 1979; Masson 1996; Gemmrich and Garrett 2012; Romero et al. 2017). The modulation is mainly attributed to nonlocal cumulative effects such as current-induced refraction. The area of modulation could, however, be very sensitive to the direction of the wave rays (Masson 1996). Furthermore, if propagating along a collinear jet, wave rays could also diverge from the center and overlap at the edges of the jet depending on the properties of the wave field. A north-south transect across the Moskenes Sound during a rising tide shows that the current is spatially more uniform (Fig. 9), which is also confirmed in previous studies (Lynge 2011). The wave ray computations (Fig. 12) did not indicate that the Moskenes Sound was particularly exposed to converging wave rays during a rising tide. However, even if the tides are well represented in the ocean model (Fig. 9), we expect more uncertainty associated with the exact location of eddies and areas of strong vorticity. This would impact the ray tracks and potentially the spatial distribution of the wave ray density.

Regarding the propagation direction of the waves relative to the current direction, conservation of wave crests [Eq. (3)] together with the conservation of wave action yields the classical result of amplitude modulation due to the Doppler shift [i.e., Eq. (2)] (Phillips 1977). In their results from the Bodega Bay, Romero et al. (2017) found that white cap coverage was consistent with focusing of wave rays due to current-induced refraction. Moreover, they found that the area of enhanced wave breaking was at the edge of a current jet suggesting that the enhanced wave breaking was also due to opposing waves and currents in a frame of reference relative to the jet. Opposing waves and currents are known to be important in tidal inlets and upwelling jets (Baschek 2005; Rapizo et al. 2017). That is, the wavelength will increase for waves propagating into a current heading in the same direction and shorten for waves opposing a current. For opposing currents, in the $x$ direction, say, the waves will grow until they reach the limit where $u=-c_{g}$, which is often referred to as the blocking velocity. Thus, wave steepening due 


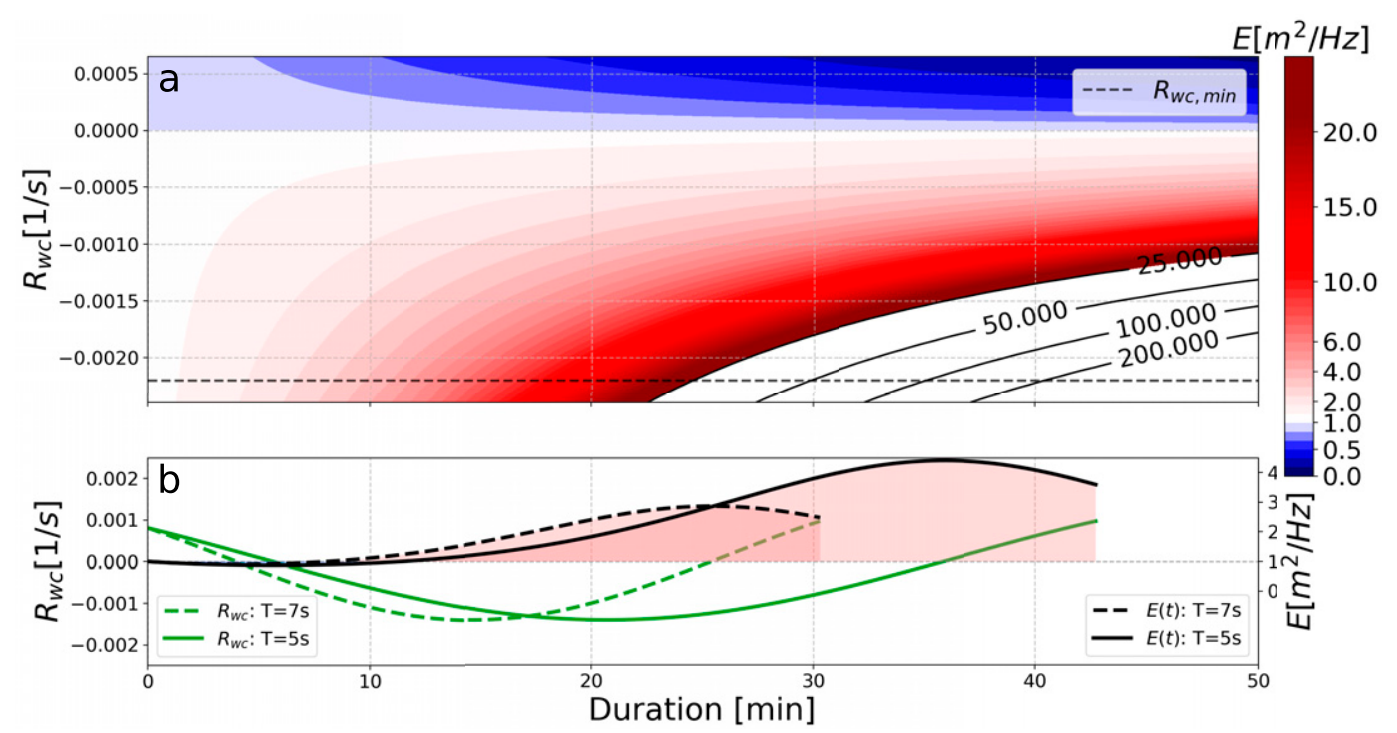

FIG. 14. A first-order estimate on the effect of relative wave convergence $R_{\mathrm{wc}}$ on wave energy density. (a) The temporal change in wave energy density $E$ is plotted as a function of values of relative wave convergence with initial value $E_{0}=1$. Shades of red and blue denote increasing and decreasing wave energy density, respectively. The black dashed line denotes the minimum negative value computed for deep water waves from the ocean model (Fig. 7e). (b) Two examples of deep water waves with $E_{0}=1$ propagating over an area with varying $R_{\mathrm{wc}}$ (green lines). The waves have periods of $T=7 \mathrm{~s}$ (black dashed line) and $T=5 \mathrm{~s}$ (black solid line) with corresponding group velocities of $c_{g}=5.5 \mathrm{~m} \mathrm{~s}^{-1}$ and $c_{g}=3.9 \mathrm{~m} \mathrm{~s}^{-1}$, respectively. Their duration corresponds to propagating a distance of $10 \mathrm{~km}$. The red and blue shaded areas correspond to an increase and decrease in $E$ with respect to $E_{0}$, respectively.

to opposing waves and currents gives rise to wave breaking by altering the critical steepness limit. This was observed in Moskstraumen as early as the seventeenth century (see the appendix). A negative Doppler shift, yielding shorter waves, can also occur for waves riding on time-varying currents similar to that of Moskstraumen, even if their direction of propagation is the same. This can be explained by considering different reference frames. If viewing, say, Moskstraumen, from shore, the direction of the waves and currents will always be aligned during an event of rising tide (right panels, Fig. 9) for waves heading eastward, both before and after current maximum. However, when following the current, the waves in front of the current maximum (i.e., in the direction of the current) will increase their wavelength in accordance with the Doppler shift. The waves behind the current maximum will then be subject to a negative current and shorten. Such phases of positive and negative acceleration are present in Moskstraumen, as can be seen from the rapid increase and decrease in current speed before and after max speed (Figs. 7c,g).

If we assume ideal conditions with a spatially uniform, timevarying current going from rest (at $t=0$ ) to a positive maximum $(t=T / 2)$ and back to rest again $(t=T)$. Waves with no dissipation propagating in the direction of the current will be stretched as the current increases and shortened back to their original shape as the current decreases back to rest. In this case

$$
\int_{0}^{T} R_{\mathrm{wc}} d t=0
$$

However, if the net wave convergence $R_{\mathrm{wc}}$ felt by the waves was negative before the current maximum occurs, then, as the waves are shortened again, they would become even steeper than before since they acquire energy due to the horizontal gradients of the current. Thus, the Doppler shift from the deaccelerating tidal current could possibly trigger wave breaking.

We expect mechanisms like current-induced refraction, wave steepening due to opposing currents as well as relative wind to also play a role in Moskstraumen. However, from the systematic occurrence of enhanced wave breaking at the $\mathrm{M}_{2}$ frequency, we argue that the mechanism in Eq. (14) seemingly constitutes a significant part of the wave-current interaction processes during rising tides in Moskstraumen. In particular during periods with calm winds and waves coming from west. Further investigation is, however, needed to assess the importance of the other forcing terms in Eq. (10), and also how small-scale processes not resolved by our ocean model would affect the wave field.

\section{Conclusions}

We have presented the first simultaneous measurements of waves and currents in one of the strongest open-ocean tidal currents in the world, namely, the Lofoten Maelstrom, or Moskstraumen. By estimating the bubble depth from a bottom mounted ADCP, and using that as a proxy for wave breaking, we find that enhanced wave breaking occurs during a rising tide when Moskstraumen is at its strongest. That is, with a period equivalent to that of the $\mathrm{M}_{2}$ tidal constituent. From a simplified expression considering specific forcing terms in the wave energy balance equation [Eq. (14)], we find that the horizontal gradients in the background flows qualitatively explain the 
enhanced wave breaking, in particular during periods with low wind speed and with waves coming from the west (during rising tides). Under such conditions, the Doppler shift of the waves possibly contribute to further steepening of the waves. More measurements are however required to assess the importance of all the forcing terms in Eq. (10).

The ADCP measurements also confirm results from previous studies which estimated the strength of Moskstraumen to reach $3 \mathrm{~m} \mathrm{~s}^{-1}$ (Gjevik et al. 1997; Moe et al. 2002; Ommundsen 2002). We do, however, expect Moskstraumen to reach even higher speeds where the Moskenes Sound is at its narrowest.

The results presented here show the importance of adding currents as forcing in spectral wave models in nearshore environments. In addition, the expression in Eq. (14) can be utilized in areas of strong current gradients to estimate their role in modulating the wave field.

Acknowledgments. This research was partly funded by the Research Council of Norway through the project MATNOC, Grant 308796. We greatly appreciate all the help from employees at Nortek AS and the Norwegian Coastal Administration who made possible the instrument deployment as well as acquiring, processing, and analyzing the ADCP data. We thank Irena Jovic at the Petter Dass Museum for providing the English translation of "The Trumpet of Nordland."

Data availability statement. The Copernicus Sentinel-1 and Sentinel-2 data are available from the National Ground Segment for Satellite Data in Norway through colhub.met.no. Norkyst 800 model data are available from https://thredds.met.no/ thredds/dodsC/sea/norkyst $800 \mathrm{~m} / 1 \mathrm{~h} /$ aggregate_be. WAM and NORA10 data are available from the Norwegian Meteorological Institute upon request. In situ ADCP data are available from Nortek AS upon request.

\section{APPENDIX}

\section{Early Wave-Current Interaction Observations in Moskstraumen}

Increased wave amplitude, and thus increased wave breaking, as a result of opposing waves and currents was observed in Moskstraumen as early as in 1685 (first published 1739) by the Norwegian priest and naturalist Peter Dass in his work Nordlands Trompet (The Trumpet of Nordland) (Dass 2007). In the following, we cite the novel observation by Dass, first in Norwegian then translated into English (translation by Theodore Jorgenson, 1954):

Og skeer det, at Vinden er Strømmen imod,

Da reyses de Bølger i dybeste Flod

Saa høye som Klippernes Toppe:

Skull' nogen fordristes at fare der da,

Han reiste der alrig med Livet ifra,

Men maatte til Bunden ned hoppe.

and

And if it so happens that counterwinds blow,

The waves will as high as the mountaintops flow
And have nothing comparable elsewhere. Should anyone dare to attempt the sea then, He would not see near ones or dear ones again; His grave would be watery bottom.

\section{REFERENCES}

Albretsen, J., A. K. Sperrevik, A. Staalstrøm, A. D. Sandvik, F. Vikeb $\varnothing$, and L. Asplin, 2011: Norkyst-800 report no. 1: User manual and technical descriptions. Fisken og havet 2, Institute of Marine Research, 48 pp., https:/www.hi.no/en/hi/nettrapporter/ fisken-og-havet/2011/fh_2-2011_til_web.

Andrews, D. G., and M. E. McIntyre, 1978: An exact theory of nonlinear waves on a Lagrangian-mean flow. J. Fluid Mech., 89, 609-646, https://doi.org/10.1017/S0022112078002773.

Ardhuin, F., and Coauthors, 2012: Numerical wave modeling in conditions with strong currents: Dissipation, refraction, and relative wind. J. Phys. Oceanogr., 42, 2101-2120, https:// doi.org/10.1175/JPO-D-11-0220.1.

- S. T. Gille, D. Menemenlis, C. B. Rocha, N. Rascle, B. Chapron, J. Gula, and J. Molemaker, 2017: Small-scale open ocean currents have large effects on wind wave heights. J. Geophys. Res. Oceans, 122, 4500-4517, https://doi.org/10.1002/2016JC012413.

Baschek, B., 2005: Wave-current interaction in tidal fronts. Rogue Waves: Proc. 14th 'Aha Huliko'a Hawaiian Winter Workshop, Honolulu, HI, University of Hawai'i at Mānoa, 131-138.

Behrens, A., J. Staneva, Ø. Saetra, and P. Janssen, 2013: Documentation of a web based source code library for WAM. Helmholtz-Zentrum Geestacht Tech. Rep., 79 pp., http://met-xpprod.customer.enonic.io/sokeresultat/_/ attachment/inline/c1fdc351-1109-47fc-9d9e-65c9f31eaccb: b52dfe2b5953103564a339bb290b83c66b1315f6/MyWave_ Report_D1.1.pdf.

Bretherton, F. P., and C. J. R. Garrett, 1968: Wavetrains in inhomogeneous moving media. Proc. Roy. Soc. London, 302A, 529-554, https://doi.org/10.1098/rspa.1968.0034.

Dass, P., 2007: Nordlands Trompet. Gyldendal, 120 pp.

Den norske los, 2018: The Norwegian Pilot Guide-Sailing Directions for the Norwegian coast, Svalbard and Jan Mayen. The Norwegian Mapping Authority, https://www.kartverket.no/ en/at-sea/nautical-publications/the-norwegian-pilot-guide-sailingdirections.

Dysthe, K. B., 2001: Refraction of gravity waves by weak current gradients. J. Fluid Mech., 442, 157-159, https://doi.org/10.1017/ S0022112001005237.

Gallet, B., and W. R. Young, 2014: Refraction of swell by surface currents. J. Mar. Res., 72, 105-126, https://doi.org/10.1357/ 002224014813758959.

Gemmrich, J., and C. Garrett, 2012: The signature of inertial and tidal currents in offshore wave records. J. Phys. Oceanogr., 42, 1051-1056, https://doi.org/10.1175/JPO-D-12-043.1.

Gjevik, B., H. Moe, and A. Ommundsen, 1997: Sources of the maelstrom. Nature, 388, 837-838, https://doi.org/10.1038/ 42159.

Guerber, H. A., 1909: Myths of the Norsemen - From the Eddas and Sagas. George G. Harrap and Company Limited, 416 pp.

Kenyon, K. E., 1971: Wave refraction in ocean currents. Deep-Sea Res. Oceanogr. Abstr., 18, 1023-1034, https://doi.org/10.1016/ 0011-7471(71)90006-4.

Komen, G. J., L. Cavaleri, M. Doneland, K. Hasselmann, S. Hasselmann, and P. A. E. M. Janssen, Eds., 1994: Dynamics and Modelling of Ocean Waves. Cambridge University Press, 554 pp., https://doi.org/10.1017/CBO9780511628955. 
Kudryavtsev, V., D. Akimov, J. Johannessen, and B. Chapron, 2005: On radar imaging of current features: 1 . Model and comparison with observations. J. Geophys. Res., 110, C07016, https://doi.org/10.1029/2004JC002505.

—, M. Yurovskaya, B. Chapron, F. Collard, and C. Donlon, 2017: Sun glitter imagery of surface waves. Part 2: Waves transformation on ocean currents. J. Geophys. Res. Oceans, 122, 13841399, https://doi.org/10.1002/2016JC012426.

Longuet-Higgins, M. S., and R. W. Stewart, 1960: Changes in the form of short gravity waves on long waves and tidal currents. J. Fluid Mech., 8, 565-583, https://doi.org/10.1017/S0022112060000803.

— discussion, with applications. Deep-Sea Res. II, 11, 529-562, https://doi.org/10.1016/0011-7471(64)90001-4.

Lynge, B. K., 2011: High resolution tidal models for the Norwegian coast. Ph.D. thesis, University of Oslo, 92 pp., https://www.duo.uio.no/bitstream/handle/10852/10729/2/ dravhandling-lynge.pdf.

Marechal, G., and F. Ardhuin, 2021: Surface currents and significant wave height gradients: Matching numerical models and high-resolution altimeter wave heights in the Agulhas current region. J. Geophys. Res. Oceans, 126, e2020JC016564, https:// doi.org/10.1029/2020JC016564.

Masson, D., 1996: A case study of wave-current interaction in a strong tidal current. J. Phys. Oceanogr., 26, 359-372, https://doi.org/10.1175/1520-0485(1996)026<0359:ACSOWI> 2.0.CO;2.

Moe, H., A. Ommundsen, and B. Gjevik, 2002: A high resolution tidal model for the area around the Lofoten Islands, northern Norway. Cont. Shelf Res., 22, 485-504, https://doi.org/10.1016/ S0278-4343(01)00078-4.

Moreira, R., and D. Peregrine, 2012: Nonlinear interactions between deep-water waves and currents. J. Fluid Mech., 691, 125, https://doi.org/10.1017/jfm.2011.436.

Ommundsen, A., 2002: Models of cross shelf transport introduced by the Lofoten maelstrom. Cont. Shelf Res., 22, 93-113, https:// doi.org/10.1016/S0278-4343(01)00069-3.

Peterson, R. G., L. Stramma, and G. Kortum, 1996: Early concepts and charts of ocean circulation. Prog. Oceanogr., 37, 1-115, https://doi.org/10.1016/S0079-6611(96)80002-4.

Phillips, O. M., 1977: The Dynamics of the Upper Ocean. 2nd ed. Cambridge University Press, 336 pp.

_- 1984: On the response of short ocean wave components at a fixed wavenumber to ocean current variations. J. Phys. Oceanogr., 14, 1425-1433, https://doi.org/10.1175/ 1520-0485(1984)014<1425:OTROSO>2.0.CO;2.

Poe, E. A., 1841: “A Descent into the Maelström." Graham's Magazine, Vol. 18, 235-241.

Quilfen, Y., and B. Chapron, 2019: Ocean surface wavecurrent signatures from satellite altimeter measurements. Geophys. Res. Lett., 46, 253-261, https://doi.org/10.1029/ 2018 GL081029.

—, M. Yurovskaya, B. Chapron, and F. Ardhuin, 2018: Storm waves focusing and steepening in the Agulhas current: Satellite observations and modeling. Remote Sens. Environ., 216, 561571, https://doi.org/10.1016/j.rse.2018.07.020.

Rapizo, H., A. V. Babanin, O. Gramstad, and M. Ghantous, 2014: Wave refraction on southern ocean eddies. Proc. 19th Australasian Fluid Mechanics Conf., Melbourne, Victoria, Australian Fluid Mechanics Society, 1-4.
,-- D. Provis, and W. E. Rogers, 2017: Current-induced dissipation in spectral wave models. J. Geophys. Res. Oceans, 122, 2205-2225, https://doi.org/10.1002/2016JC012367.

Reistad, M., Ø. Breivik, H. Haakenstad, O. J. Aarnes, B. R. Furevik, and J.-R. Bidlot, 2011: A high-resolution hindcast of wind and waves for the North Sea, the Norwegian Sea, and the Barents Sea. J. Geophys. Res., 116, C05019, https://doi.org/ 10.1029/2010JC006402.

Romero, L., 2019: Distribution of surface wave breaking fronts. Geophys. Res. Lett., 46, 10 463-10 474, https://doi.org/10.1029/ 2019 GL083408.

, L. Lenain, and W. K. Melville, 2017: Observations of surface wave-current interaction. J. Phys. Oceanogr., 47, 615-632, https://doi.org/10.1175/JPO-D-16-0108.1.

—, D. Hypolite, and J. C. McWilliams, 2020: Submesoscale current effects on surface waves. Ocean Modell., 153, 101662, https://doi.org/10.1016/j.ocemod.2020.101662.

Shchepetkin, A. F., and J. C. McWilliams, 2005: The regional oceanic modeling system (ROMS): A split-explicit, freesurface, topography-following-coordinate oceanic model. J. Phys. Oceanogr., 9, 347-404, https://doi.org/10.1016/ j.ocemod.2004.08.002.

Smith, G., 2017: Fishing trawler Iselin capsized at Moskstraumen near Norway. Maritime Herald, 30 March, accessed 3 November 2020, www.maritimeherald.com/2017/fishing-trawler-iselin-capsizedat-moskstraumen-near-norway/.

Strand, K., Ø. Breivik, G. Pedersen, F. Vikeb $\varnothing$, S. Sundby, and K. Christensen, 2020: Long-term statistics of observed bubble depth versus modeled wave dissipation. J. Geophys. Res. Oceans, 125, e2019JC015906, https://doi.org/10.1029/2019JC015906.

Thorpe, S., 1986: Measurements with an automatically recording inverted echo sounder; ARIES and the bubble clouds. J. Phys. Oceanogr., 16, 1462-1478, https://doi.org/10.1175/ 1520-0485(1986)016<1462:MWAARI >2.0.CO;2.

Tolman, H. L., 1990: The influence of unsteady depths and currents of tides on wind-wave propagation in shelf seas. J. Phys. Oceanogr., 20, 1166-1174, https://doi.org/10.1175/ 1520-0485(1990)020<1166:TIOUDA > 2.0.CO;2.

Verne, J., 1869: Vingt mille lieues sous les mers. Magasin d'éducation et de récrátion, $449 \mathrm{pp}$.

Villas Bôas, A. B., and W. R. Young, 2020: Directional diffusion of surface gravity wave action by ocean macroturbulence. J. Fluid Mech., 890, R3, https://doi.org/ 10.1017/jfm.2020.116.

_ B. D. Cornuelle, M. R. Mazloff, S. T. Gille, and F. Ardhuin, 2020: Wave-current interactions at meso- and submesoscales: Insights from idealized numerical simulations. J. Phys. Oceanogr., 50, 3483-3500, https://doi.org/10.1175/JPO-D-20-0151.1.

Vincent, C. E., 1979: The interaction of wind-generated sea waves with tidal currents. J. Phys. Oceanogr., 9, 748-755, https://doi.org/ 10.1175/1520-0485(1979)009<0748:TIOWGS >2.0.CO;2.

Wang, D., H. Wijesekera, E. Jarosz, W. Teague, and W. Pegau, 2016: Turbulent diffusivity under high winds from acoustic measurements of bubbles. J. Phys. Oceanogr., 46, 1593-1613, https://doi.org/10.1175/JPO-D-15-0164.1.

WW3DG, 2019: The WAVEWATCH III development group. User manual and system documentation of WAVEWATCH III. Tech. Note 333, NOAA/NWS/NCEP/MMAB, 465 pp., https://github.com/NOAA-EMC/WW3/wiki/files/manual.pdf. 